\title{
LA CONTRIBUCIÓN DE LAS NUEVAS TECNOLOGÍAS A LA EDUCACIÓN PLURILINGÜE DE LOS FUTUROS DOCENTES EN COMUNIDADES CON LENGUA MINORITARIA.
}

Resumen: La educación plurilingüe y digital de los futuros educadores se presenta como un reto para las instituciones. La movilidad entre los pueblos y el desarrollo de las Tecnologías de la Comunicación e Información han creado nuevas necesidades educativas que será necesario abordar. En el caso de las comunidades bilingües con presencia de una lengua minoritaria el desafío es aún mayor, ya que se trata de fomentar un plurilingüismo aditivo, lo cual requiere una buena planificación. Y este es el trabajo que estamos desarrollando en la Facultad de Humanidades y Ciencias de la Educación de la Universidad Mondragón. Estamos experimentado un plan de educación plurilingüe y digital en los grados de Educación Infantil y Educación Primaria.

Palabras clave: Educación plurilingüe; educación digital; plurilingüismo aditivo; formación inicial de profesorado.

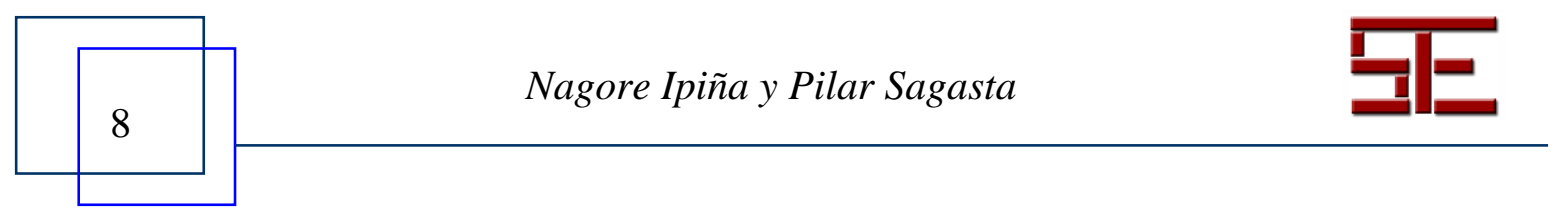




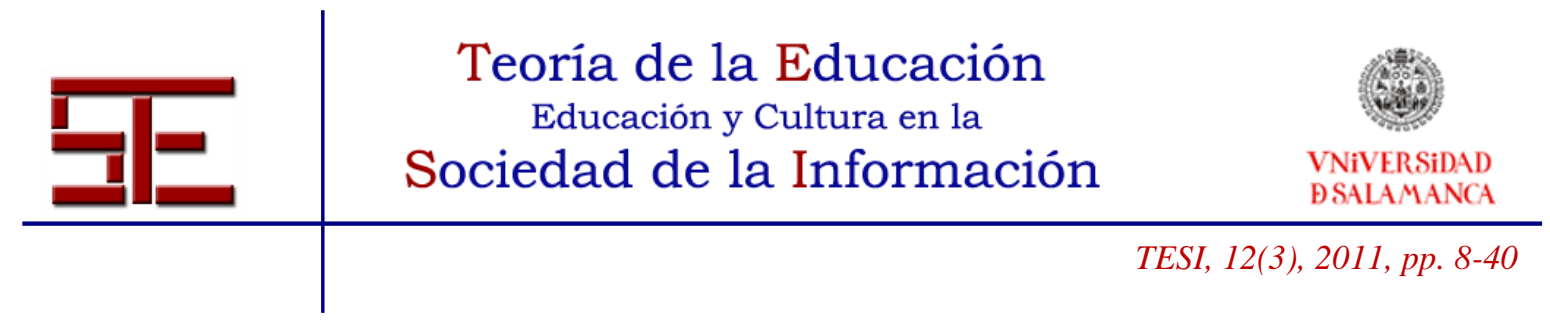

\section{CONTRIBUTION OF NEW TECHNOLOGIES IN FUTURE TEACHERS' MULTILINGUAL EDUCATION IN COMMUNITIES WITH A MINORITY LANGUAGE}

Abstract: Future teachers' multilingual education and digital literacy present a challenge for our institutions. Mobility between different countries and the development of the Information and Communication Technologies have set up new educational needs to deal with. Moreover, if the aim is to promote additive multilingualism in bilingual settings with a minority language, the challenge is even bigger due to the fact that a good planning is required. And this is the work that we are developing in the Faculty of Humanities and Education in the University of Mondragon. We are experimenting with a multilingual and digital plan in Infant and Primary Education Degrees.

Keywords: Multilingual education; digital literacy; additive multilingualism; initial teacher training.

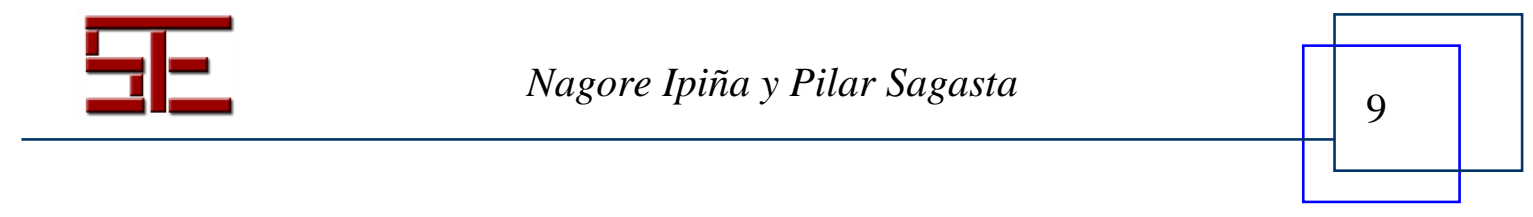




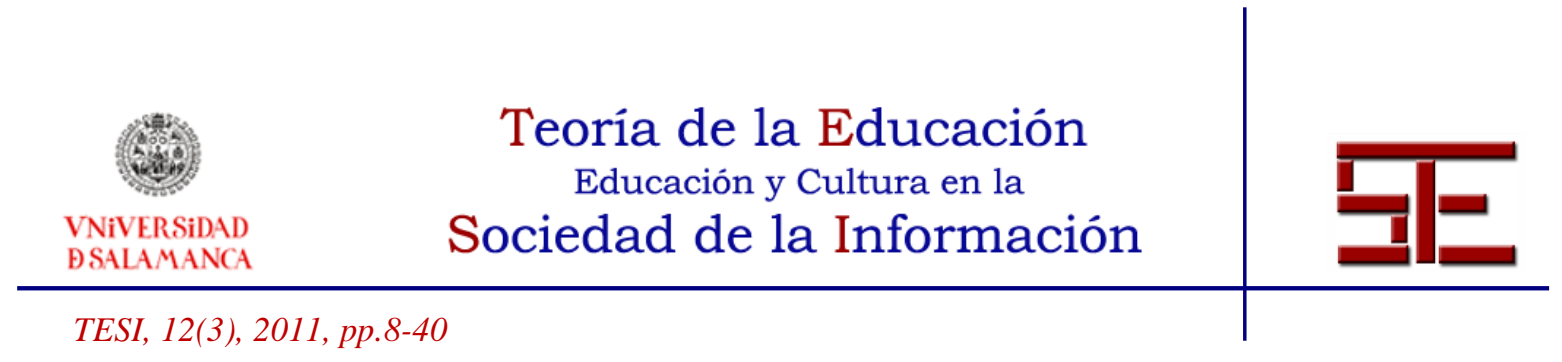

\section{LA CONTRIBUCIÓN DE LAS NUEVAS TECNOLOGÍAS A LA EDUCACIÓN PLURILINGÜE DE LOS FUTUROS DOCENTES EN COMUNIDADES CON LENGUA MINORITARIA}

Fecha de recepción: 18/08/2011; fecha de aceptación: 14/010/2011; fecha de publicación: 30/11/2011

$\begin{aligned} & \text { Nagore Ipiña } \\ & \text { nipina@ mondragon.edu }\end{aligned}$
Mondragon Unibertsitatea
Pilar Sagasta
psagasta@ mondragon.edu
Mondragon Unibertsitatea

\section{1.- INTRODUCCIÓN}

La educación lingüística de los futuros docentes se presenta como un reto al cual deberíamos prestar su debida atención. Por una parte, la Comisión de las Comunidades Europeas (2008) promueve en sus Estados miembros la necesidad de fomentar el conocimiento de la lengua materna y de otras dos lenguas para impulsar el diálogo y el respeto por las diferentes culturas que conforman el mosaico europeo. Este conocimiento de las otras lenguas y culturas puede contribuir al diálogo intercultural y a la cohesión social. Y puede, asimismo, favorecer la movilidad entre los miembros de la Comunidad Europea, de manera que todos ellos tengan acceso a las mismas oportunidades. La Comisión reconoce además que las personas multilingües representan un activo valioso porque pueden actuar como vínculo entre las diversas culturas. Por lo tanto, a juicio de la Comisión, los Estados miembros de la Comunidad Europea deben diseñar políticas educativas que fomenten la competencia plurilingüe.

Por otra parte, las aulas de los países de la Comunidad Europea están cada vez más integradas por estudiantes cuya lengua familiar no se corresponde con la lengua de instrucción en la escuela. Y a este respecto, la Comisión de las Comunidades Europeas (2008) aconseja formar a los futuros docentes en técnicas adecuadas para que puedan enseñar su propia lengua como segunda lengua o lengua extranjera. Asimismo, se incide cada vez más en el aprendizaje de la lengua a través de áreas curriculares no lingüísticas, al objeto de promover un aprendizaje más significativo, tanto de la lengua como del área curricular en cuestión. Se interpreta como un enfoque más adecuado para

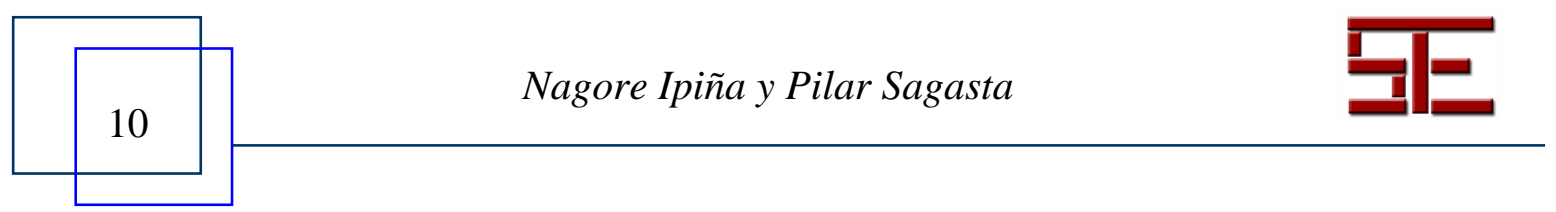




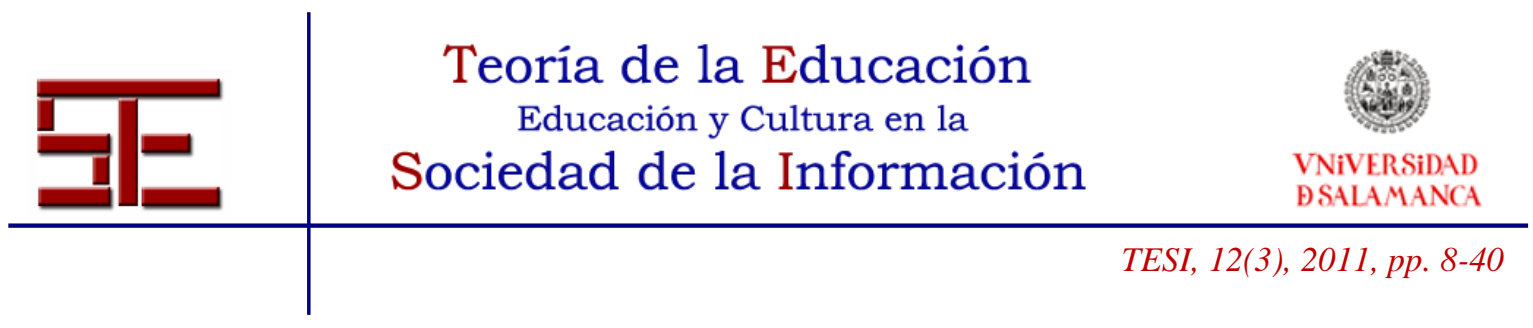

el desarrollo de la competencia plurilingüe, porque el aprendizaje formal de la lengua pocas veces promueve un nivel alto de competencia (Baetens Beardmore, 2001).

Además, a menudo el uso de la lengua en dichas clases es bastante artificial y la competencia plurilinguie requiere crear contextos de uso significativo, es decir, utilizar la lengua con sentido. Por consiguiente, las instituciones educativas deben integrar en sus planes de formación estrategias para que los futuros docentes desarrollen competencias pedagógicas que les permitan afrontar estos nuevos desafíos con éxito.

Si además el contexto donde se desarrolla la formación de los futuros docentes se caracteriza por ser una comunidad bilingüe con presencia de una lengua minoritaria en proceso de normalización, los planes de educación lingüística deben responder a esta realidad. Los futuros docentes necesitarán desarrollar una competencia plurilingüe y, asimismo, estar capacitados para gestionar un Proyecto Educativo plurilingüe.

Junto con los retos lingüísticos presentados, los futuros docentes se encuentran frente a una nueva revolución social de transformación multidimensional que propulsada por las Tecnologías de la Información y la Comunicación (TIC en adelante) ha rediseñado todas las áreas de la sociedad. La hegemonía de la imagen y el sonido, la rapidez, la colaboración y, cómo no, la presencia de la red de redes han promovido una reflexión pedagógica dirigiendo todos los sistemas y niveles educativos hacia un replanteamiento de sus metodologías.

La educación, como apunta Morín (1999), es la fuerza del futuro de las sociedades ya que ella constituye uno de los elementos más poderosos para realizar el cambio. Hace más de diez años, en 1998, el informe de la Unesco advertía de que para contribuir a la satisfacción de las necesidades de aprendizaje deberíamos aprovechar la sinergia ofrecida por el nuevo flujo de información y la capacidad de comunicación de todos los agentes activos de la sociedad. Debido a la importancia de la educación en el desarrollo de las sociedades, y más aún en la Sociedad del Conocimiento, y frente a las nuevas posibilidades, el objetivo es por lo tanto diseñar espacios y modelos educativos (léase formal e informal) para que los estudiantes de cualquier nivel puedan desarrollar capacidades y competencias para poder desenvolverse de manera dinámica y efectiva en un mundo cambiante y sobrepasado de información (Francisco Amat, 2011). Y es en este sentido también donde las instituciones deberán formar a los futuros docentes en la utilización sociocultural y constructiva de las TIC.

Y estos son los desafíos que nos gustaría abordar en la Facultad de Humanidades y Ciencias de la Educación de la Universidad Mondragón. De hecho estamos experimentando un plan de educación plurilingüe en los estudios de grado de Educación Infantil y Educación Primaria y también examinando las posibilidades que ofrecen las herramientas del universo 2.0. Así que en los párrafos que siguen a continuación

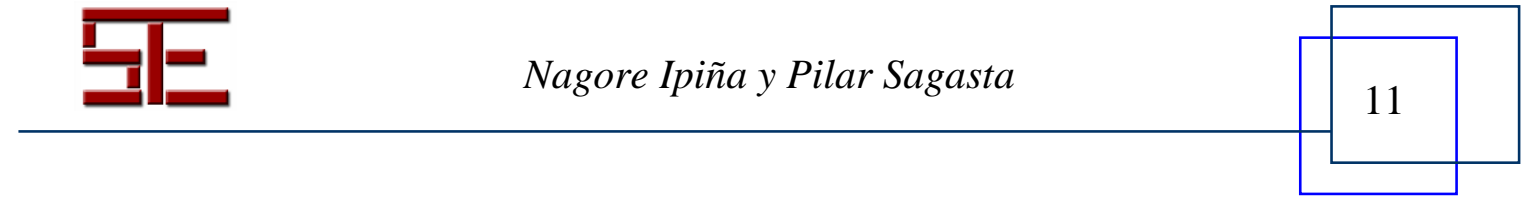




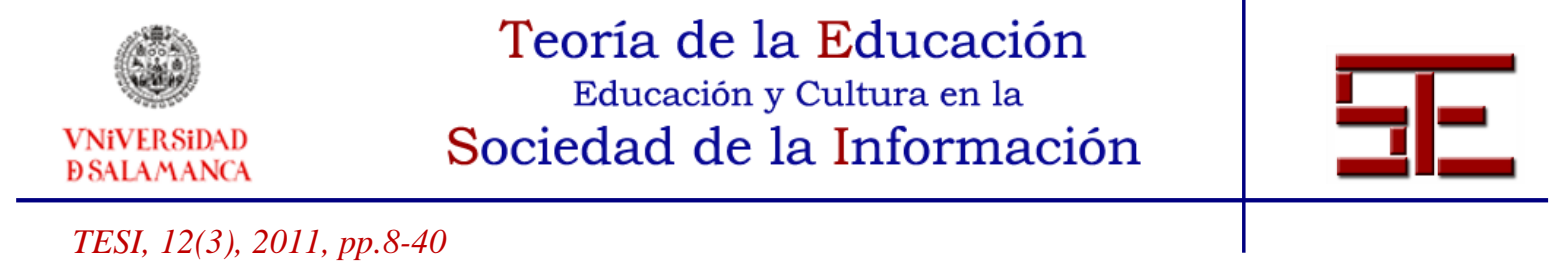

daremos cuenta de nuestro contexto, de las características del plan de educación plurilingüe y de la experiencia desarrollada con la wiki para analizar su contribución al desarrollo de la competencia plurilingüe.

\section{2.- CARACTERÍSTICAS DEL CONTEXTO DONDE LOS FUTUROS DOCENTES DESEMPEÑARÁN SU LABOR}

El diseño de un plan de educación plurilingüe requiere una lectura exhaustiva del contexto sociolingüístico y sociocultural donde se ubica el plan de formación que se pretende desarrollar, porque el proceso de enseñanza-aprendizaje es situado. Se produce en un contexto determinado, con presencia o ausencia de determinadas características que deben ser tenidas en cuenta, para que el proceso sea significativo. No se puede atribuir sentido a un plan de formación que no atienda a las características contextuales. En nuestro caso concreto se trata de futuros docentes, por lo tanto, necesitamos dar cuenta de los modelos lingüísticos en la comunidad educativa.

En la Comunidad Autónoma Vasca conviven dos lenguas oficiales, el castellano, que goza de gran prestigio social por su presencia en los diferentes ámbitos de uso, y el euskera, en vías de normalización lingüística. El euskera es la lengua familiar de un tercio de la población y la escuela desempeña y ha desempeñado una labor esencial en la normalización de su uso, a través de los modelos de escolarización y los planes de normalización linguiística (Gardner y Zalbide, 2005). Las siguientes tablas muestran las cifras de pre-matrícula para el curso 2011-2012 en los diferentes modelos lingüísticos. En el modelo A, la lengua de instrucción es el castellano y el euskera se estudia como asignatura. En el modelo B, tanto el euskera como el castellano son lenguas de instrucción. En el modelo D, la lengua de instrucción es el euskera y el castellano es objeto de estudio como asignatura y en el modelo $\mathrm{X}$ no se estudia el euskera.

Tabla 1. Pre-matrícula en Educación Infantil según los modelos lingüísticos

\begin{tabular}{|l|l|l|l|l|l|}
\hline $2011-2012$ & A & B & D & X & Total \\
& 3.720 & 20.857 & 70.007 & 436 & 95.020 \\
& $3,91 \%$ & $(21,95 \%)$ & $(73,67 \%)$ & $(0,45 \%)$ & \\
\hline
\end{tabular}

Eustat, 2011.

Tabla 2. Pre-matrícula en Educación Primaria según los modelos lingüísticos

\begin{tabular}{|l|l|l|l|l|l|}
\hline $2011-2012$ & $\mathrm{~A}$ & $\mathrm{~B}$ & $\mathrm{D}$ & $\mathrm{X}$ & Total \\
\hline & 8.044 & 32.774 & 79.163 & 855 & 120.836 \\
& $(6,66 \%)$ & $(27,12 \%)$ & $(65,51 \%)$ & $(0,71 \%)$ & \\
\hline
\end{tabular}

Eustat, 2011.

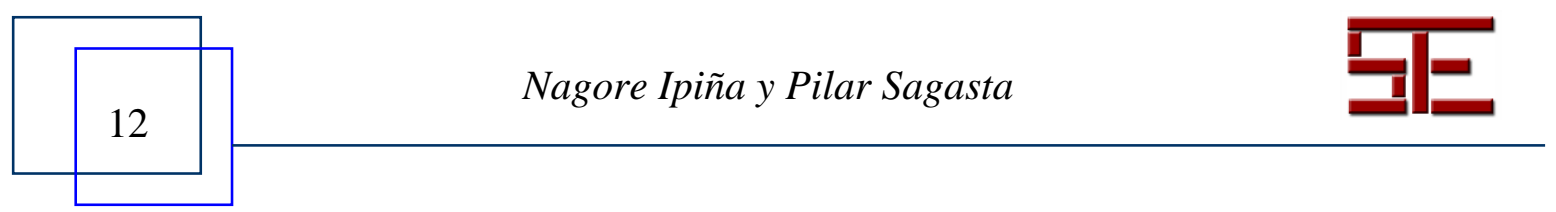




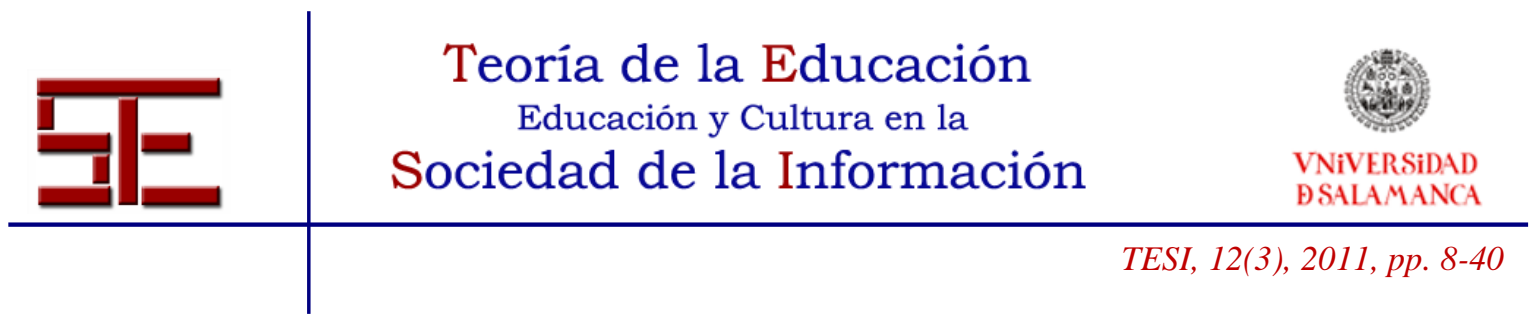

Tabla 3. Pre-matrícula en Educación Secundaria Obligatoria según los modelos lingüísticos

\begin{tabular}{|l|l|l|l|l|l|}
\hline $2011-2012$ & A & B & D & X & Total \\
\hline & 6.478 & 11.059 & 19.738 & 539 & 37.814 \\
& $(17,13 \%)$ & $(29,24 \%)$ & $(52,19 \%)$ & $(1,42 \%)$ & \\
\hline
\end{tabular}

Eustat, 2011.

Por otra parte, el inglés se introduce en la mayoría de los centros a la edad de cuatro años y son cada día más los centros que optan por trabajar algunos contenidos curriculares de manera integrada con el inglés (Cenoz, 1998; Elortza y Muñoa, 2008; ISEI-IVEI, 2007; Ruiz de Zarobe y Lasagabaster, 2010). Actualmente, la Consejería de Educación del Gobierno Vasco promueve el plan de trilingüismo que comporta entre otros aspectos un aumento del número de horas dedicadas a la enseñanza en inglés. Y este es el contexto donde los futuros docentes de la Comunidad Autónoma Vasca desempeñarán su función $\mathrm{y}$, por lo tanto, los planes de educación lingüística en formación inicial del profesorado deben tener en cuenta las características de dicho contexto.

\section{3.- BASES QUE SUSTENTAN EL PLAN DE EDUCACIÓN PLURILINGÜE DISEÑADO}

Dadas las características del contexto que acabamos de describir, en la Facultad de Humanidades y Ciencias de la Educación de la Universidad Mondragón hemos diseñado un plan de educación lingüística que tiene como objetivo el desarrollo de un plurilingüismo aditivo (Lambert, 1979; Cenoz y Genesee, 1998) en euskera, castellano e inglés. Un plurilingüismo que se desarrolla de manera integrada y armoniosa y que no perjudica ni al desarrollo de la primera ni al de la segunda lengua, no las sustituye, porque en tal caso estaríamos fomentado un plurilingüismo sustractivo. Los avances que se producen en cada una de las lenguas contribuyen al desarrollo de la competencia plurilingüe de estos estudiantes, porque las competencias académicas, las relacionadas con los procesos de lectoescritura, son interdependientes (Cummins, 1983).

Partimos además de una concepción holística de la competencia plurilingüe; de acuerdo con Grosjean (1992) entendemos que una persona bilingüe no es la suma de dos monolingües, que tiene una configuración lingüística propia que se caracteriza por la constante interacción y coexistencia de dos lenguas. Algo similar ocurre con la competencia plurilingüe, la persona plurilingüe utiliza una u otra lengua, o dos a la vez, en los casos de alternancia de código, en función de la situación de comunicación. Cook

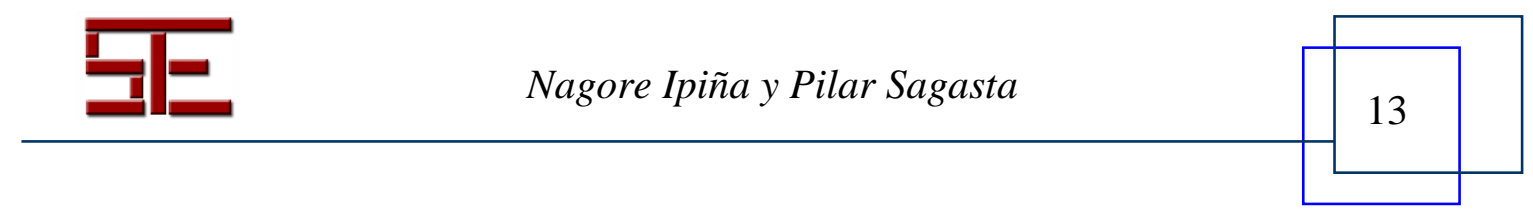




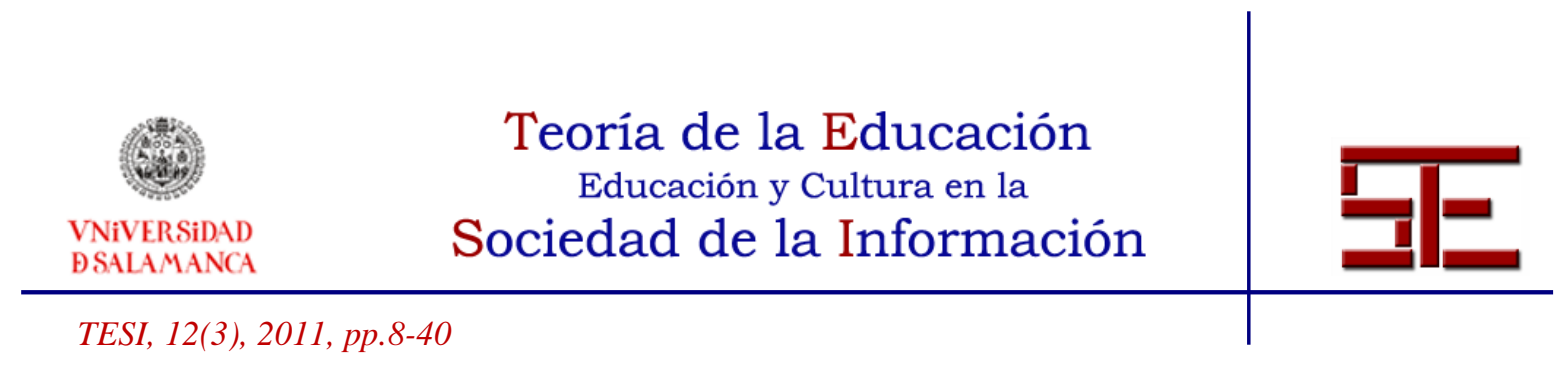

(1995) defiende una postura similar y habla de pluricompetencia y Jessner (1997) destaca el carácter dinámico de la competencia plurilingüe. A lo largo de la vida, una persona puede ir pasando del monolingüismo al bilingüismo o al plurilingüismo en función de sus necesidades de comunicación. Por lo tanto, la competencia lingüística de un plurilingüe está conformada por una serie de subsistemas lingüísticos que interactúan de modo dinámico y están sometidos a constante variación. La figura que presentamos a continuación ilustra las bases que sustentan el plan de educación lingüística que hemos diseñado:

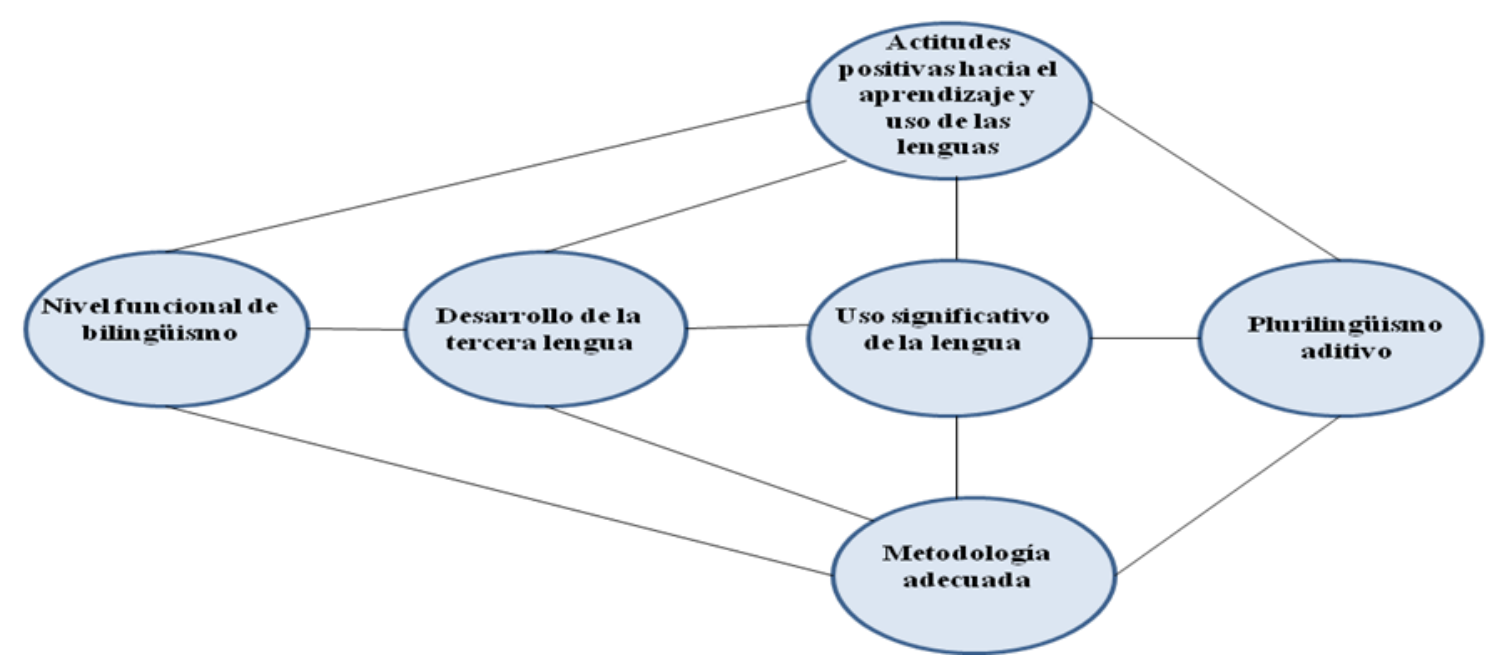

Figura 1. Bases que sustentan el plan de educación lingüística de los futuros docentes

La investigación desarrollada en el ámbito de la tercera lengua ha puesto de manifiesto que el nivel de bilingüismo desarrollado en la primera y segunda lengua es un factor que influye en el desarrollo de la tercera lengua. Así lo han demostrado los estudios realizados en la Comunidad Autónoma Vasca (Cenoz, 1992; Lasagabaster, 1998; Sagasta, 2000) y en Catalunya (Bernaus, 1996; Muñoz, 2000; Sanz, 2000). Por lo tanto, en comunidades donde conviven dos lenguas oficiales, el plan de educación lingüística debe priorizar la lengua con menor presencia social en los diferentes ámbitos de uso, de modo que los estudiantes en cuestión desarrollen un bilingüismo funcional; un bilingüismo que les permita utilizar ambas lenguas indistintamente. Diversos estudios llevados a cabo en diferentes contextos constatan la importancia de la instrucción formal en lengua minoritaria (Swain et al., 1990; Thomas, 1988). También los estudios desarrollados en la Comunidad Autónoma Vasca muestran que los estudiantes que más

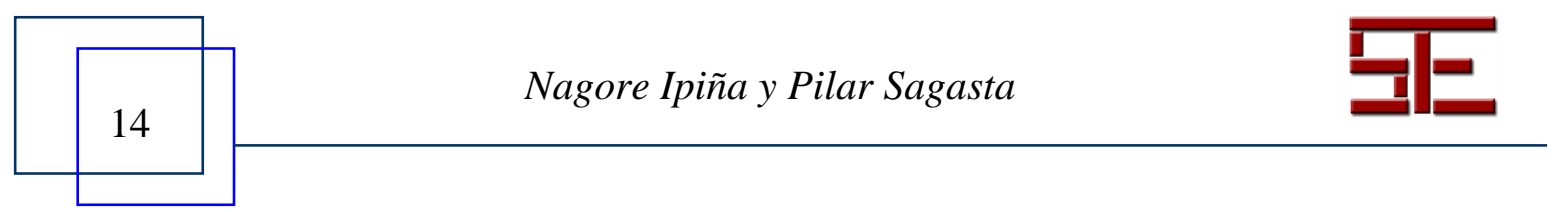




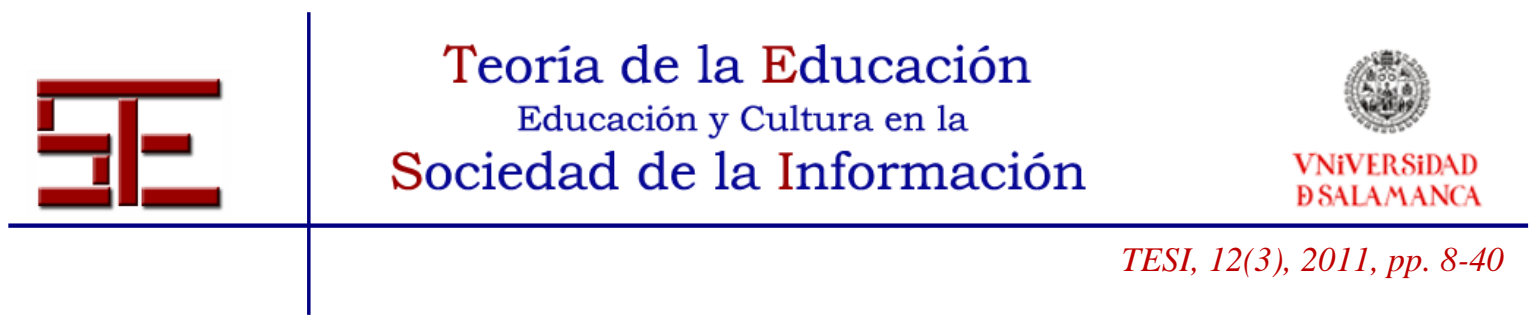

han utilizado el euskera como lengua de instrucción son los que mayor nivel de bilingüismo han adquirido (ISEI-IVEI, 2005). Por consiguiente, nuestro plan de educación lingüística favorece el uso del euskera para compensar el déficit que se produce en los diferentes ámbitos de uso social en relación a las dos lenguas, el euskera y el castellano.

Además del factor bilingüismo funcional en primera y segunda lengua, hemos seleccionado una serie de aspectos que pueden influir en el desarrollo de la competencia plurilingüe. Uno de esos aspectos lo constituyen las actitudes hacia las lenguas. Autores como Gardner (1985), pioneros en el estudio de la influencia de las actitudes en el desarrollo de la segunda lengua, afirman que los resultados de una experiencia de segunda lengua, bien sea en un contexto formal como natural, siempre son lingüísticos y no lingüísticos, porque además de adquirir competencia lingüística, se desarrollan también actitudes y valores que a su vez influirán en posteriores experiencias de aprendizaje. Gardner admite que el contexto social ejerce un gran influjo en las actitudes. En los últimos años se han realizado varios estudios que confirman la influencia de las actitudes en la lengua minoritaria, mayoritaria y extranjera (Cenoz, 1991; Espi, 1994; Lasagabaster, 2003, 2005; Madariaga, 1994; Sagasta, 2000).

Otro aspecto que consideramos importante es el uso significativo de las lenguas, al que ya nos referíamos en la introducción al mencionar la diferencia entre el aprendizaje formal en las clases de lengua tradicionales y el aprendizaje integrado de lengua y áreas curriculares no linguiísticas. En este último caso el área de conocimiento en cuestión crea un contexto de uso de la lengua auténtico que, por lo tanto, facilita el aprendizaje significativo de la lengua. A juicio de Coyle, Hood y Marsh (2010), en las clases tradicionales de lengua el objetivo de la comunicación es la práctica de la lengua en base a una progresión gramatical determinada, y no tanto la negociación de significados. Sin embargo, en un contexto donde se trabaja una disciplina específica se crean situaciones de interacción auténticas donde se hace necesaria la negociación de significados, condición que favorece el aprendizaje de la lengua (Swain, 2000). En definitiva, se utiliza la lengua para aprender y se aprende a utilizar la lengua (Coyle, Hood y Marsh, 2010).

No obstante, el aprendizaje integrado de contenidos curriculares y lengua supone un verdadero reto cara a la intervención pedagógica, porque no se trata simplemente de cambiar la lengua de instrucción y actuar como si se tratara de la lengua familiar de los estudiantes (Met, 1998). Es necesario guiar ese proceso de enseñanza-aprendizaje utilizando estrategias docentes que permitan a los estudiantes comprender y producir significados en el área objeto de aprendizaje. Estas estrategias de intervención han sido principalmente estudiadas en aquellos contextos donde los aprendizajes escolares se

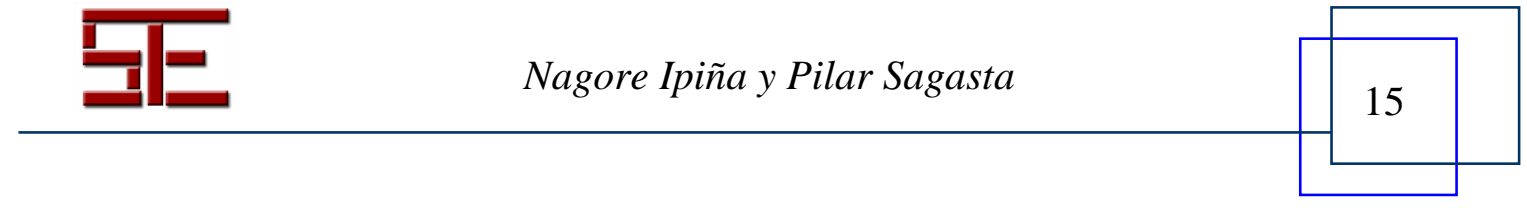




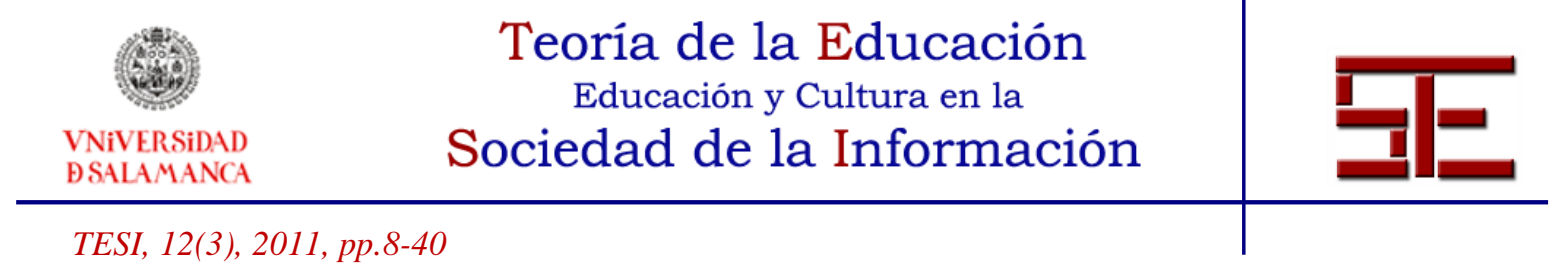

promueven a través de una lengua no familiar (Short, 1991; Carrasquillo y Rodríguez, 1996; Echevarria et al., 2000; Coelho, 2005) o una lengua minoritaria (Laplante, 1996, 2000, 2005; Serra Santasusana, 2004; Sainz Osinaga y Sagasta Errasti, 2005).

En resumen, estas serían las bases que sustentan el plan de educación plurilingüe que estamos experimentando desde el curso 2009/2010 en los grados de Educación Infantil y Educación Primaria: damos prioridad a la lengua minoritaria como lengua de instrucción en aras a desarrollar un plurilingüismo aditivo; trabajamos las tres lenguas, euskera, castellano e inglés a través de las materias curriculares y para ello realizamos una doble planificación (contenidos y lengua), tomando como eje la materia en cuestión e incidimos en las actitudes hacia las lenguas a través de talleres. A continuación daremos detalles sobre el plan diseñado.

\section{4.- EL PLAN DE EDUCACIÓN PLURILINGÜE PARA LOS FUTUROS DOCENTES}

Al incorporarse a la facultad, la primera materia que trabajan los estudiantes es Definición y contextualización de la profesión de maestro y desarrollo de competencias generales de 10 ECTS, cuyo objetivo principal es reflexionar sobre ellos mismos, conocer el contexto donde cursarán sus estudios a lo largo de cuatro años y reflexionar sobre la profesión docente, sobre lo que significa educar. Y al compartir las características del contexto, los estudiantes se familiarizan con el plan de Educación plurilingüe y se organizan talleres donde comienzan a reflexionar sobre su propia autobiografía lingüística: qué lenguas conocen, desde cuándo, cuáles utilizan, dónde y por qué, qué sienten con respecto a cada una de las lenguas, cuál ha sido su experiencia de aprendizaje, etc. Los estudiantes trabajan a nivel individual y grupal y, de este modo, van reflexionando y compartiendo sus experiencias lingüísticas y culturales y, al mismo tiempo, van definiendo sus objetivos con respecto al plan de educación lingüística. En esta materia se recogen además las primeras producciones escritas de los estudiantes en las tres lenguas. Asimismo, se organizan talleres para trabajar la exposición oral y se graban las exposiciones orales que realizan los estudiantes en la materia.

Estas producciones se retoman en una materia de 6 ECTS que hemos diseñado para trabajar las habilidades comunicativas básicas en euskera, castellano e inglés, que también se imparte en primer curso y que tiene una duración de 9 semanas. Para definir dicha habilidades básicas hemos tenido en cuenta las competencias lingüísticas, comunicativas y académicas que los docentes necesitan para desempeñar su labor profesional. El siguiente cuadro muestra el diseño realizado.

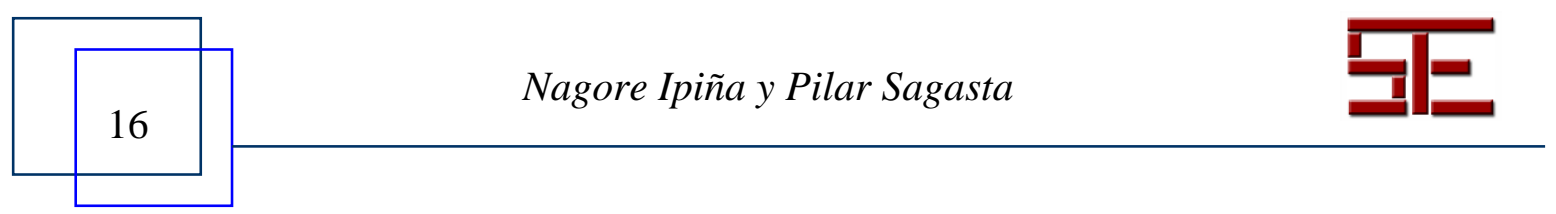




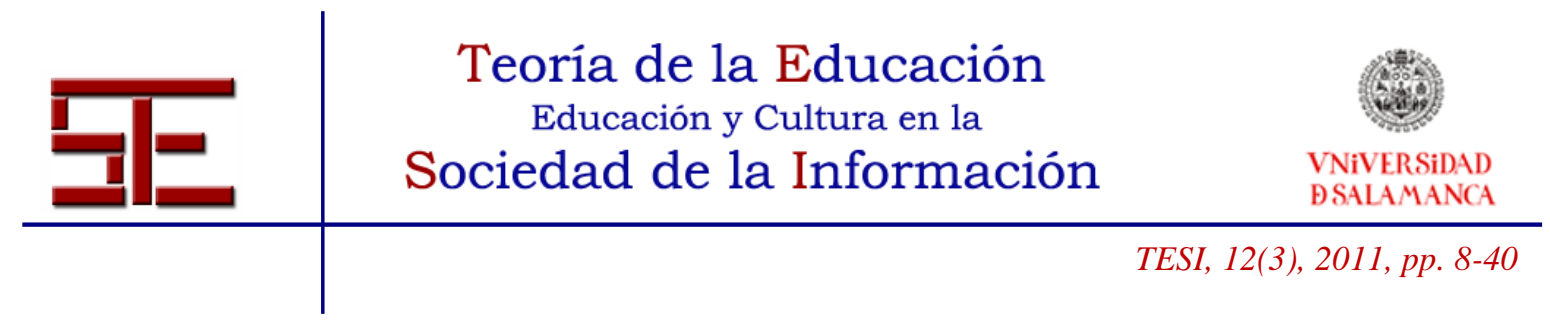

Tabla 4. Diseño de la materia Habilidades Comunicativas Básicas de 6 ECTS

\begin{tabular}{|c|c|c|}
\hline Dispositivos didácticos & Lenguas & Contenidos \\
\hline $\begin{array}{l}\text { Recursos tecnológicos } \\
\text { aplicados a la escritura }\end{array}$ & $\begin{array}{l}\text { Euskera } \\
\text { Castellano } \\
\text { Inglés }\end{array}$ & $\begin{array}{l}\text { - Recursos tecnológicos para escribir } \\
\text { adecuadamente en euskera, castellano } \\
\text { e inglés: correctores automáticos, } \\
\text { diccionarios, tablas de ejercicios, } \\
\text { corrector personal }\end{array}$ \\
\hline $\begin{array}{l}\text { Síntesis-esquema (ligado con } \\
\text { estrategias de lectura) }\end{array}$ & $\begin{array}{lr}\text { Lectura } & \text { en } \\
\text { castellano } & y \\
\text { producción final en } \\
\text { euskera }\end{array}$ & $\begin{array}{l}\text { - Estrategias de comprensión: identificar } \\
\text { la superestructura, las ideas principales } \\
\text { y las secundarias; comprender el léxico } \\
\text { específico; etc. } \\
\text { - Síntesis-esquema-mapa conceptual }\end{array}$ \\
\hline $\begin{array}{l}\text { Actitudes lingüísticas } \\
\text { Texto expositivo: artículo de } \\
\text { divulgación }\end{array}$ & Castellano & $\begin{array}{l}\text { - Características principales del artículo } \\
\text { divulgativo } \\
\text { - Cuestiones normativas y textuales del } \\
\text { castellano } \\
\text { - Euskera y castellano juntos en la } \\
\text { escuela y en la sociedad }\end{array}$ \\
\hline $\begin{array}{l}\text { Euskera estándar y registros } \\
\text { en la escuela } \\
\text { Texto explicativo: informe }\end{array}$ & Euskera & $\begin{array}{l}\text { - Características principales del informe } \\
\text { - Normativa del euskera y cuestiones } \\
\text { estilísticas } \\
\text { - Historia del euskera unificado y } \\
\text { registros en la escuela }\end{array}$ \\
\hline $\begin{array}{l}\text { Lengua y géneros. } \\
\text { Texto de opinión: la columna } \\
\text { y el foro }\end{array}$ & Euskera y castellano & $\begin{array}{l}\text { - Principales características del artículo } \\
\text { de opinión } \\
\text { - Las lenguas y los géneros personales }\end{array}$ \\
\hline $\begin{array}{l}\text { Pensando sobre el inglés en } \\
\text { inglés } \\
\text { E-mail }\end{array}$ & Inglés & $\begin{array}{l}\text { - Principales características del e-mail y } \\
\text { cartas formales } \\
\text { - Perfil lingüístico en inglés: } \\
\text { experiencias previas, dificultades, } \\
\text { objetivos... } \\
\text { - Estrategias de aprendizaje del inglés }\end{array}$ \\
\hline La literatura, fuente de placer & $\begin{array}{l}\text { Euskera } \\
\text { Castellano } \\
\text { Inglés }\end{array}$ & $\begin{array}{l}\text { - Análisis y creación de textos literarios } \\
\text { en las tres lenguas }\end{array}$ \\
\hline $\begin{array}{l}\text { Lengua y cultura: trabajo } \\
\text { creativo }\end{array}$ & $\begin{array}{l}\text { Euskera } \\
\text { Castellano } \\
\text { Inglés }\end{array}$ & $\begin{array}{l}\text { - Diseño y producción del trabajo } \\
\text { creativo } \\
\text { - Presentación oral }\end{array}$ \\
\hline
\end{tabular}

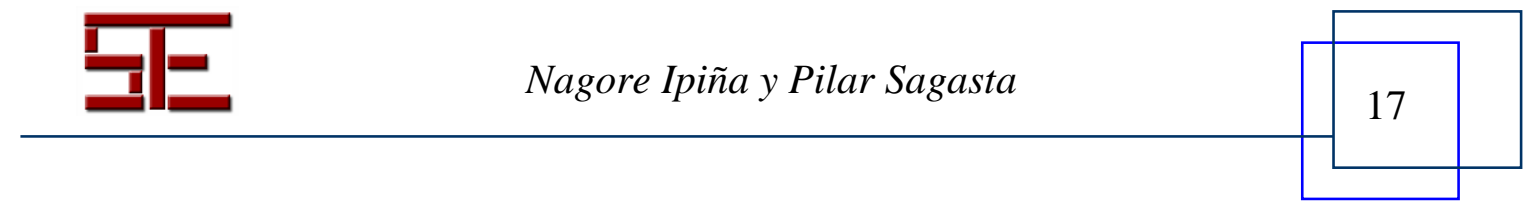




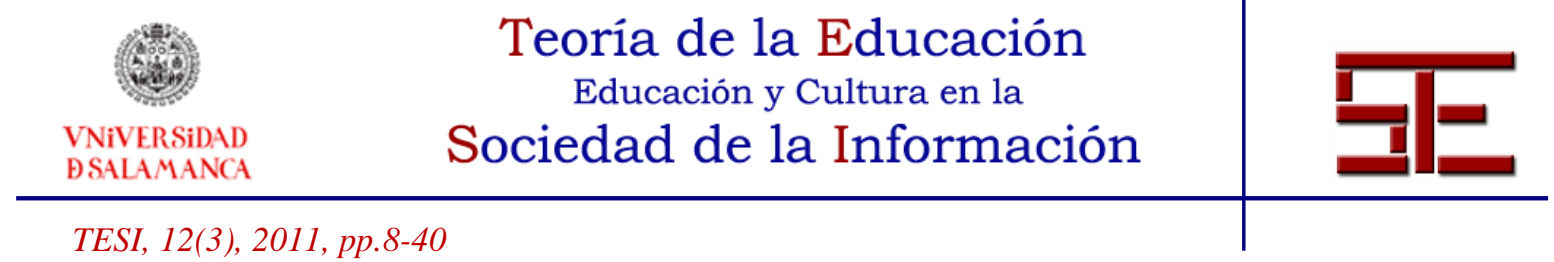

Además de esta materia que se imparte en primer curso, el euskera y el castellano se trabajan de manera integrada con otras materias de los grados de Educación Infantil y Primaria. La siguiente tabla muestra algunos ejemplos de las competencias que se trabajan en las diferentes materias de los dos primeros cursos.

Tabla 5. El trabajo integrado de materias curriculares y euskera y castellano

\begin{tabular}{|l|l|l|}
\hline \multicolumn{1}{|c|}{ Curso } & \multicolumn{1}{|c|}{ Materia } & \multicolumn{1}{|c|}{ El trabajo de la lengua } \\
\hline Primero & $\begin{array}{l}\text { Perspectiva global de la } \\
\text { realidad 6 ECTS }\end{array}$ & $\begin{array}{l}\text {-Producción y evaluación de } \\
\text { un informe. } \\
\text {-Evaluación de un texto de } \\
\text { opinión. }\end{array}$ \\
\hline Primero & $\begin{array}{l}\text { Bases psicopedagógicas de la } \\
\text { educación infantil y primaria } \\
\text { 8 ECTS }\end{array}$ & $\begin{array}{l}\text {-Evaluación de una } \\
\text { exposición oral. }\end{array}$ \\
\hline Segundo & Practicum 8 ECTS & $\begin{array}{l}\text {-Competencias relacionadas } \\
\text { con la descripción y la } \\
\text { reflexión sobre la práctica } \\
\text { docente. Competencias } \\
\text { relacionadas con la } \\
\text { presentación oral: la } \\
\text { adecuación al contexto } \\
\text { comunicativo }\end{array}$ \\
\hline Segundo & $\begin{array}{l}\text { Organización escolar y yodión escrita de nota } \\
\text { participación de la familia 6 } \\
\text { ECTS }\end{array}$ & $\begin{array}{l}\text {-Producción } \\
\text { para la familia. } \\
\text {-Entrevista con la familia }\end{array}$ \\
\hline
\end{tabular}

Como se puede apreciar en la tabla, en las diferentes materias del currículum se retoman algunas competencias trabajadas en la materia Habilidades Comunicativas Básicas y se evalúan.Otras veces se trabajan competencias necesarias para el desarrollo de las materias, como ocurre en las materias de segundo curso. En ambos casos los profesores de lengua trabajan de manera coordinada con los tutores de las materias.

En relación al inglés, hemos de manifestar que se trabaja de manera integrada con materias del currículum en ambos grados, como lo muestra la tabla que presentamos a continuación:

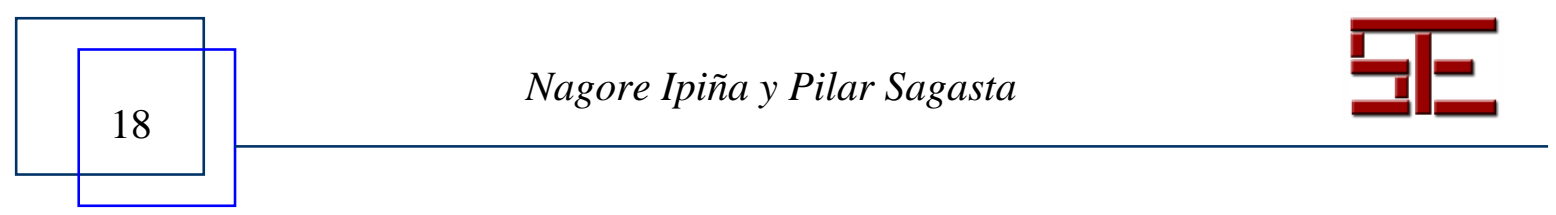




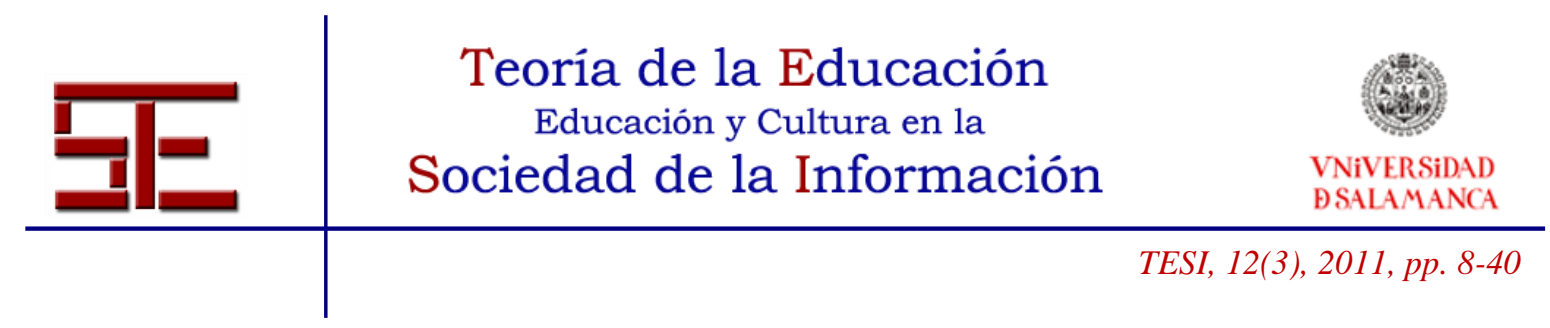

Tabla 6. Aprendizaje integrado de materias curriculares e inglés

\begin{tabular}{|c|l|l|}
\hline Curso & \multicolumn{1}{|c|}{ Grado en Educación Infantil } & \multicolumn{1}{c|}{ Grado en Educación Primaria } \\
\hline Primero & \multicolumn{2}{|c|}{ La educación en Europa y en el mundo global. Buenas prácticas. 6 ECTS } \\
\hline Segundo & $\begin{array}{l}\text { La enseñanza-aprendizaje precoz de } \\
\text { segundas lenguas en contextos } \\
\text { plurilingües. 6 ECTS }\end{array}$ & $\begin{array}{l}\text { La enseñanza-aprendizaje de las lenguas } \\
\text { por medio de contenidos curriculares en } \\
\text { contextos de L2 lengua curricular. 6 ECTS }\end{array}$ \\
\hline
\end{tabular}

En primer curso se imparte en ambos grados la materia La Educación en Europa y en el mundo global. Buenas Prácticas, a la que nos referiremos más adelante, ya que es esta materia la que hemos seleccionado para experimentar la contribución de la wiki al trabajo colaborativo en la producción escrita en inglés.

En segundo curso se imparte en el grado de Educación Infantil, la materia Enseñanzaaprendizaje precoz de segundas lenguas en contextos plurilingües. Como ya lo señalábamos al describir el contexto de la Comunidad Autónoma Vasca, actualmente está muy generalizada la introducción precoz del inglés y la mayoría de los centros lo introducen a la edad de cuatro años. Por consiguiente, entendemos que los tutores de Educación Infantil deben desarrollar competencias que les permitan comprender los procesos de adquisición de lenguas en contextos plurilingües y deben desarrollar estrategias que les permitan intervenir en dichos contextos. Y este es el objetivo principal de dicha materia.

En relación al grado de Educación Primaria, en segundo curso trabajamos la Enseñanzaaprendizaje de las lenguas por medio de contenidos curriculares en contextos de L2 lengua curricular. En la Comunidad Autónoma Vasca la mayoría de las familias matricula a sus hijos en los modelos de inmersión total o parcial al euskera, como ya lo mostrábamos mediante cifras al describir el contexto. Y sin embargo, únicamente un tercio de la población escolar tiene el euskera como lengua familiar, por lo cual los futuros docentes deben desarrollar estrategias de intervención para que los estudiantes realicen los cursos y aprendan la lengua con éxito. Por otra parte, son cada vez más los centros escolares que ofrecen la posibilidad de cursar materias curriculares, o parte de ellas en inglés. Por consiguiente, existe una doble razón para formar a los futuros docentes de la Comunidad Autónoma Vasca en estrategias que les permitan gestionar las materias curriculares a través de una segunda lengua o una lengua extranjera. Asimismo, el hecho de trabajar ellos mismos estas materias en inglés les ayudará a comprender mejor qué significa realizar el currículum mediante una lengua que no se domina bien, qué estrategias favorecen ese aprendizaje y cómo se puede ayudar a estudiantes que se encuentren en dicha situación. La propia Comisión de las Comunidades Europeas (2008) ha detectado la necesidad de este tipo de formación:

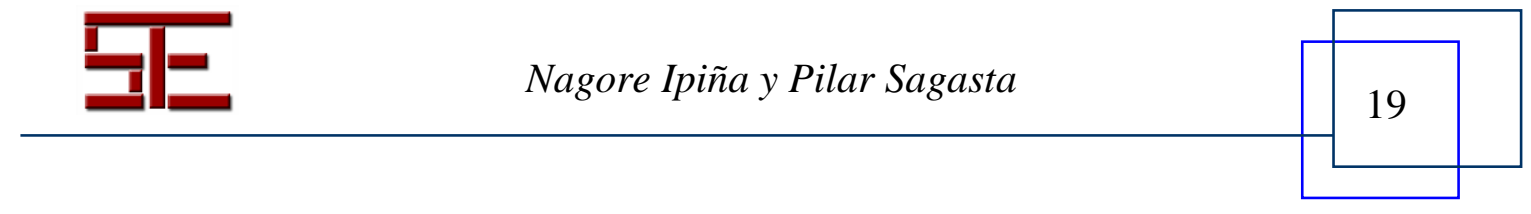




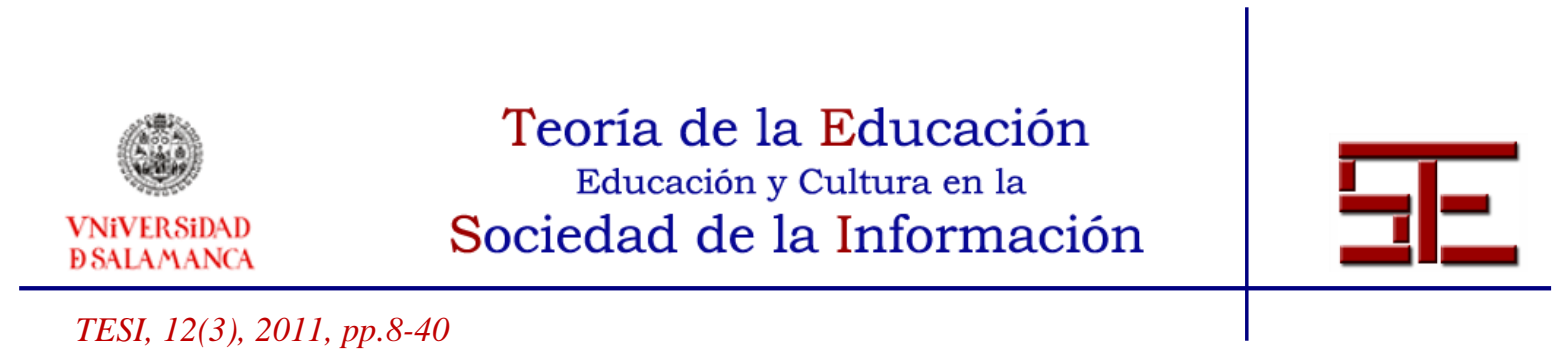

"Los profesores de la lengua nacional, que se enfrentan cada vez más con aulas integradas por estudiantes de lenguas maternas diferentes, deberían recibir formación en las técnicas adecuadas para que puedan enseñar su propia lengua como segunda lengua o lengua extranjera" (Comisión, 2008, 12).

Además de todos estos aspectos, los estudiantes tienen la posibilidad de realizar tanto parte de sus prácticas como parte de sus estudios en países europeos y estas experiencias favorecen el desarrollo de competencias lingüísticas e interculturales. A este respecto la Comisión de las Comunidades Europeas afirma que "los estudiantes de Erasmus consideran que la mejora de sus conocimientos lingüísticos constituye el principal beneficio de su estancia en el extranjero. Los planes de estudios y de formación deben aprovechar plenamente los intercambios, las asociaciones y los hermanamientos electrónicos con centros de otros países" (Comisión, 2008, 9-10).

En resumen, este es el plan de educación plurilingüe que estamos experimentando con los futuros docentes de Educación Infantil y Educación Primaria. A nuestro juicio presenta una serie de características novedosas que nos gustaría destacar: partimos de un marco integrado de desarrollo de las lenguas, porque, como ya lo comentábamos en un principio, entendemos la competencia plurilingüe como una competencia holística conformada por varios subsistemas lingüísticos y no como la suma de varias competencias monolingües. Retomamos las competencias trabajadas en una materia y en una lengua y damos a los estudiantes la posibilidad de utilizarlas en otra materia y en otra lengua, condición indispensable para que se produzca transferencia de aprendizaje (Cummins, 2005). Hemos conseguido dotar al aprendizaje de la lengua de un contexto auténtico; las lenguas las utilizamos para construir conocimientos y destrezas en áreas curriculares y esto permite a los estudiantes construir conocimientos y destrezas en las lenguas del currículum. Y, además, trabajamos las actitudes hacia las lenguas para incidir en la consciencia de los estudiantes con respecto al uso de las lenguas.

Asimismo, estamos experimentando también con herramientas procedentes del universo $2.0 \mathrm{y}$ estamos interesados en conocer mejor las posibilidades que nos ofrecen dichas herramientas para el desarrollo de la competencia plurilinguie. Uno de los dispositivos didácticos que hemos utilizado es la wiki, ya que entendemos que puede fomentar el trabajo colaborativo en tareas de producción escrita. En las líneas que siguen a continuación explicaremos por qué hemos optado por la wiki, daremos datos de la experiencia desarrollada en una de las materias y escucharemos las voces de estudiantes $\mathrm{y}$ tutores que han participado en dicha experiencia.

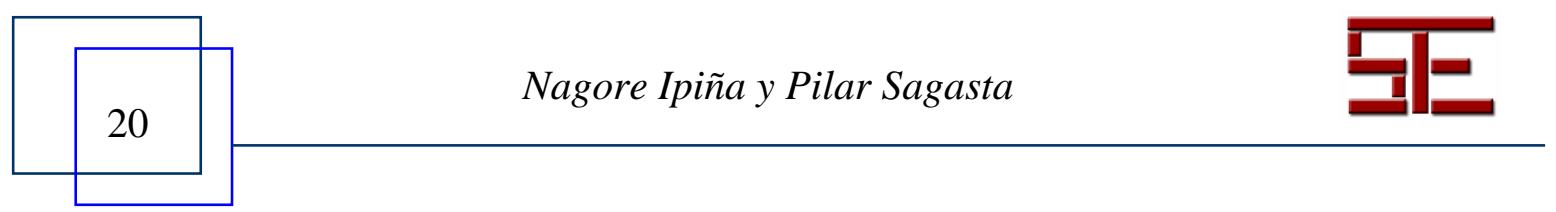




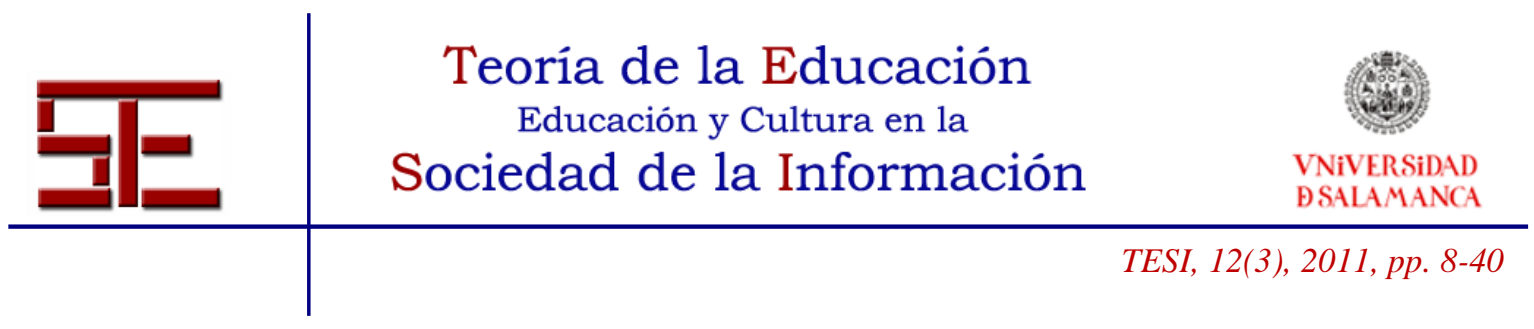

\section{5.- APORTACIONES DE LAS WIKIS A LA EDUCACIÓN}

Como consecuencia de la Sociedad del Conocimiento y del crecimiento de Internet, la red nos ha ofrecido diversas aplicaciones dirigidas a fomentar la adquisición del conocimiento de manera interactiva. Bien, si hasta hace no mucho el desarrollo de espacios virtuales ha sido bastante individualista, la colaboración está hoy en día adquiriendo un área primordial (Barberá, 2009). Esta emergencia colaborativa puede ser claramente observable en herramientas como la wiki, la cual es además considerada por autores como Barberá (2009) una de las herramientas más académicas del universo 2.0. La wiki, desarrollada por Ward Cunningham en 1994, comenzó a utilizarse por programadores e informáticos, pero rápidamente se descubrió su potencial educativo.

Fue en 1998 cuando Guzdial diseñó la primera wiki educativa (Guzdial, 1999). Desde entonces, y gracias al impulso propiciado por Wikipedia, las wikis han sido utilizadas en considerables experiencias educativas (Augar et al., 2004; Peña et al., 2006; Schneider, 2004; Stahl, 2008).

Cabe mencionar que las investigaciones en torno a las wikis no son todavía abundantes (Bower et al., 2006) y menos aún en educación superior donde su utilización es especialmente nueva (Chen et al., 2005; Chao, 2007; Evans, 2006; Schaffer et al., 2006).

La wiki, definida de manera simple por Area (2009) como un editor on-line abierto para la escritura colaborativa, nos lleva a caracterizarla como un producto de proceso inacabado en todos sus estadios. Lamb (2004) considera que las wikis se componen de cuatro principios básicos como son el cambio continuo, la facilidad de uso, la relación interna y externa, y la continuidad dinámica. Barton (2004) y Leuf y Cunnignham (2001) añaden un quinto principio relativo a la reflexión propiciada por comentarios externos. Recapitulando lo dicho, podemos mencionar que la wiki es una página web que permite que cualquier participante (autor y audiencia al mismo tiempo), desde cualquier lugar y momento pueda editar esta página web de manera colaborativa (Paker y Chao, 2007).

Las wikis, por consiguiente, exigen una visión compartida de la tarea a realizar (Barberá, 2009). En este sentido, el compromiso, la negociación de significados y el sentimiento de pertenencia se hacen patentes en cada momento ofreciendo una perspectiva mucho más social al proceso de enseñanza-aprendizaje.

Las investigaciones realizadas en torno a las wikis en los procesos de enseñanzaaprendizaje (ver Davis, 2004; Gimeno y García, 2009; Hazari, North y Moreland, 2009; Toker, Moseley y Chow, 2008; Trentin, 2009; Xiao y Lucking, 2008) demuestran que la colaboración predicada teóricamente se lleva a cabo en términos reales. Los resultados

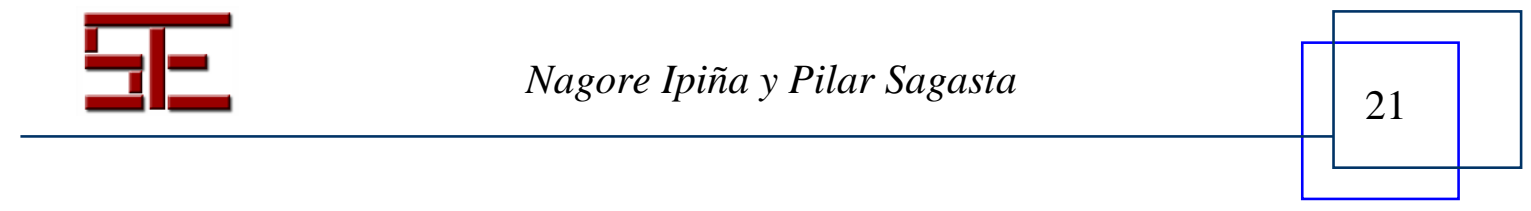




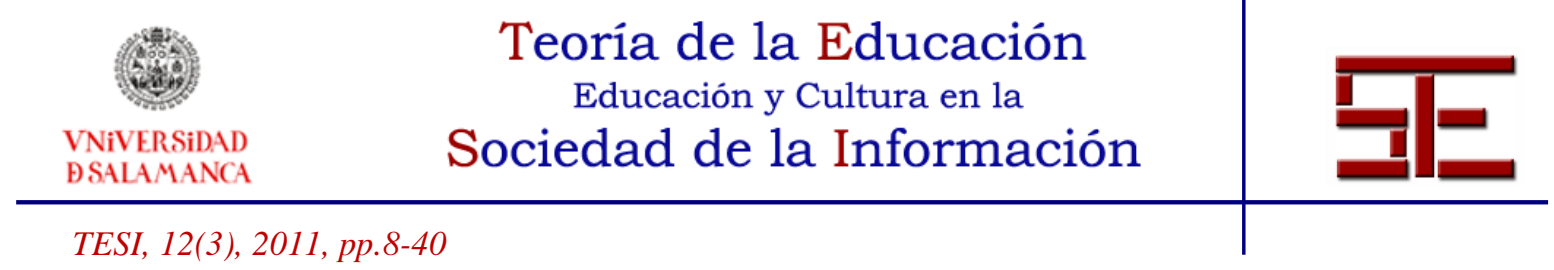

también muestran que las wikis promueven espacios de alto grado de interacción y negociación social.

Además de lo mencionado, autores como Martín y Alonso (2009) o Parker y Chao (2007) inciden en el paralelismo existente entre las características de las wikis y el modelo constructivista, permitiendo que los estudiantes construyan su propio aprendizaje mediante la interacción con los demás estudiantes así como con el medio. Relacionando los aspectos desarrollados sobre las wikis y situándonos en procesos de enseñanza-aprendizaje de lenguas extranjeras, Davison (2008) y Xiao y Lucking (2008) coinciden en que los estudiantes desarrollan un proceso cognitivo común al desarrollar una wiki y al aprender una lengua. Según estos autores el desarrollo de una wiki requiere de tres procesos principales: input, output y feedback. De la misma manera estos tres procesos son básicos en el aprendizaje de una lengua. La continua comunicación fomentada por la wiki promueve, según Mak y Conian (2008) y Morgan y Smith (2008), el desarrollo de competencias de lectoescritura. Además de lo mencionado, Gimeno y García (2009) añaden que el desarrollo de una wiki en los procesos de enseñanza-aprendizaje en lengua extranjera promueve la toma de conciencia sobre el aprendizaje de lenguas, permite el control sobre las actitudes lingüísticas incidiendo positivamente en la motivación y tolera la negociación entre estudiantes y entre tutor y alumno.

Teniendo en cuenta el contexto sociolingüístico y sociocultural en el que nos situamos y la utilización de TIC en el aula, el siguiente apartado describirá un ejemplo de la utilización de wikis en un aula de Aprendizaje Integrado de Lenguas y Contenido donde los diferentes apartados desarrollados en el marco teórico encuentran un espacio compartido.

\section{6.- EDUCATION IN EUROPE AND THE GLOBAL WORLD. GOOD PRACTICES}

La materia "Education in Europe and the Global World. Good Practices", implementada por primera vez en 2009 y obligatoria para todos los estudiantes del Grado de Educación Infantil y Educación Primaria, consta de 6 ECTS. El objetivo de esta materia es que los estudiantes adquieran una visión global de los sistemas educativos incidiendo en aspectos relativos a la calidad, el plurilingüismo y la multiculturalidad. La materia presenta una gran relevancia con el perfil profesional, ya, que como mencionábamos en un principio, la realidad de las aulas ha cambiado tanto que los futuros docentes necesitan familiarizarse con esta realidad.

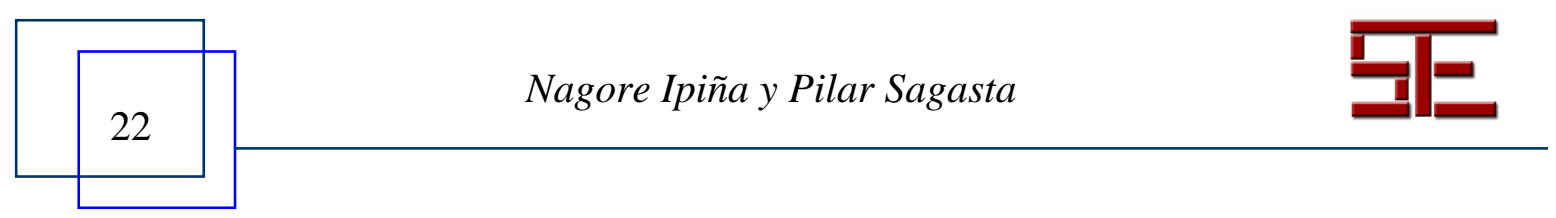




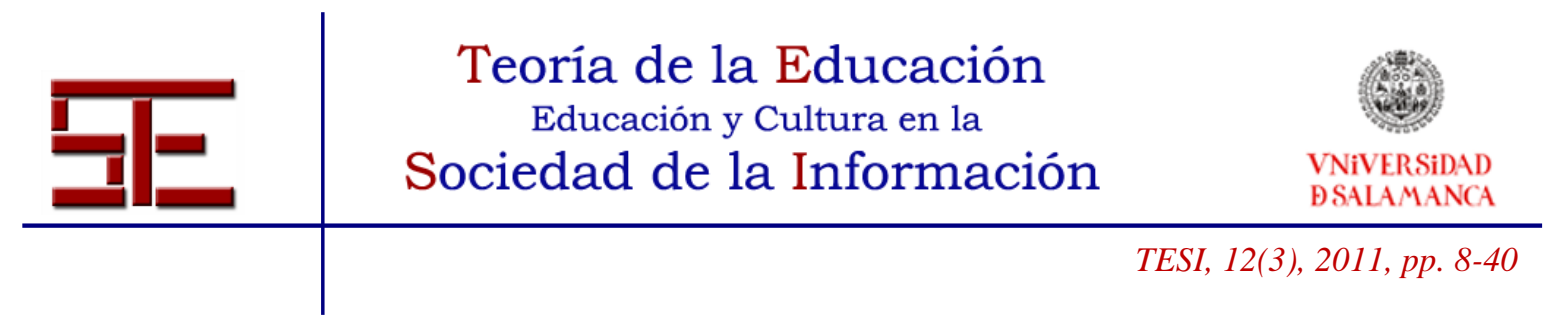

Para lograr estos objetivos los estudiantes deberán desarrollar competencias tanto específicas como transversales. Entre las específicas, y situándonos en un contexto de integración de contenidos curriculares y lenguas, los estudiantes deberán desarrollar competencias relativas tanto a la lengua como al contenido. Siendo las competencias de trabajo en equipo, comunicación efectiva y aprender a aprender vitales en los futuros docentes, los estudiantes deberán mostrar también su desarrollo durante la materia.

La materia, compuesta por 4 secuencias didácticas y un proyecto que recoge lo más significativo de las mismas y funciona como nexo de unión, se lleva a cabo durante diez semanas en el orden que muestra la siguiente figura.

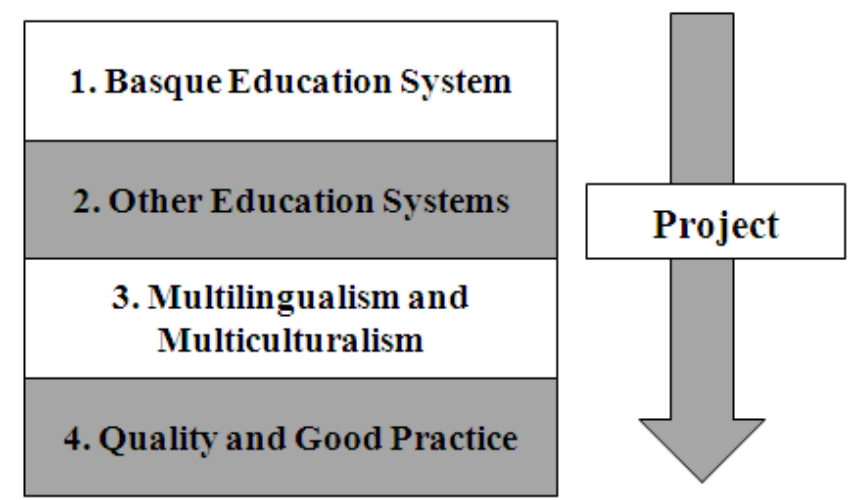

Figura 2. Secuencias didácticas de la materia.

A la hora de secuenciar los conocimientos, la materia parte de lo más cercano y conocido para el alumnado como es el sistema educativo no universitario del País Vasco. Esta primera secuencia se trabaja también en otra materia en la lengua materna además de ser un aspecto conocido por haberlo vivido en primera persona. Esta secuencia permite a los estudiantes adquirir el idioma básico para trabajar en la segunda secuencia las similitudes y diferencias entre distintos sistemas educativos europeos y también de otros lugares del mundo. La tercera secuencia, relativa al multilingüismo y la multiculturalidad, comienza por profundizar en la educación bilingüe/multilingüe. Los estudiantes parten de esta característica y conocen y comparan el sistema con otros sistemas europeos o mundiales que también cuentan con dos lenguas co-oficiales, una de las cuales es minoritaria. El fenómeno de multiculturalidad también se trabaja en esta secuencia debido a su creciente importancia como lo hemos venido señalando. La última secuencia se centra en la calidad en educación. Una vez más se parte de sus conocimientos previos para poder profundizar en el tema. Las buenas prácticas en

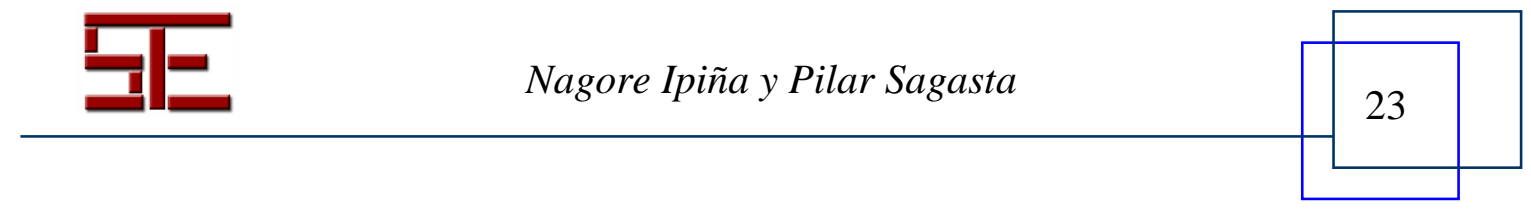




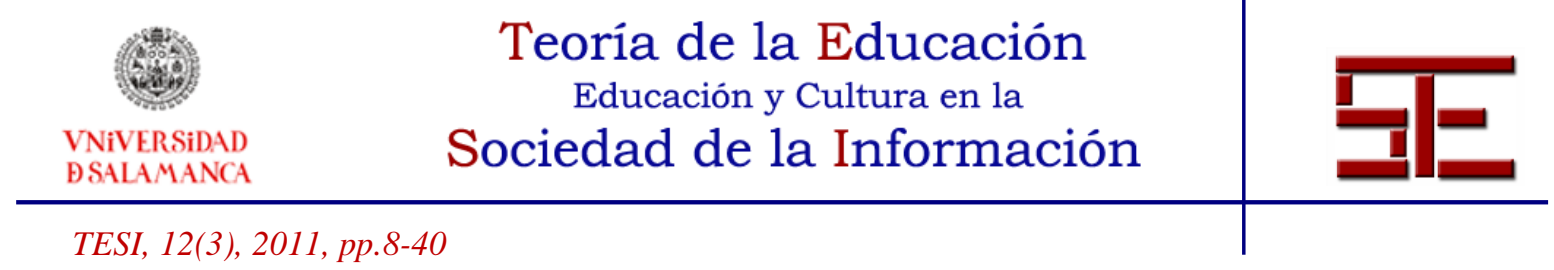

educación constituyen el último bloque a trabajar. Relacionadas con la calidad, los estudiantes analizan ejemplos de buenas prácticas en su entorno para posteriormente identificar ejemplos concretos en otros sistemas educativos.

El proyecto, pieza clave en el progreso de la materia, integra todas las secuencias anteriormente descritas. Para ello los estudiantes comienzan a trabajar en pequeños grupos, 4/5 estudiantes por grupo, desde el comienzo de la materia. Se asigna un centro europeo, otro de otra parte del mundo y un tercero opcional a seleccionar entre los centros en los que los miembros del grupo han cursado sus estudios. El objetivo del mismo es que los estudiantes investiguen acerca de los sistemas educativos de los países en los que se encuentran los centros asignados y trabajen los diversos aspectos desarrollados durante la materia. Finalmente, los estudiantes realizan una comparación de los factores desarrollados. Los resultados de su investigación se presentan en forma de informe y de exposición oral.

Lo que resulta innovador en esta materia es que los estudiantes deben realizar el proyecto por medio de una wiki. Cada grupo construirá su propia wiki como plataforma para la escritura colaborativa del informe. En lo que a la formación tecnológica de los estudiantes se refiere, el primer día y junto con la presentación de la materia, los estudiantes reciben un taller sobre las wikis incidiendo tanto en su filosofía de colaboración como en su utilización amigable.

Con el fin de describir la experiencia del curso académico 2010-2011, los siguientes apartados esbozarán la muestra y algunos datos recogidos de cuestionarios de satisfacción y reflexiones realizadas por los estudiantes al finalizar la materia.

\section{7.- RESULTADOS DE ESTA EXPERIENCIA}

La muestra de esta experiencia está formada por 184 estudiantes, de los cuales el 71,2\% son mujeres y el 28,8\% hombres. La edad media de los estudiantes es de 19,6 años, por lo cual podemos decir que son, a priori, como los describe Prensky (2001), nativos digitales o pertenecen a la conocida generación red (Tapscott, 1998).

En cuanto a las especialidades se refiere, el 47,3\% de los participantes, es decir 87 estudiantes, están matriculados en el grado de Educación Infantil y el 52,7\% de la muestra corresponde a los estudiantes de Educación Primaria. En cuanto a las diferentes especialidades de este último grado, el $31,6 \%$ pertenece a la especialidad general de Educación Primaria, el 18,9\% a la especialidad de Lengua Extranjera, el 31,6\% a la de Educación Física y, por último, el 17,9\% a la especialidad de Educación Especial.

En lo referente al marco sociolingüístico de la muestra, la siguiente tabla muestra un resumen de datos acordes al marco teórico que sustenta esta experiencia.

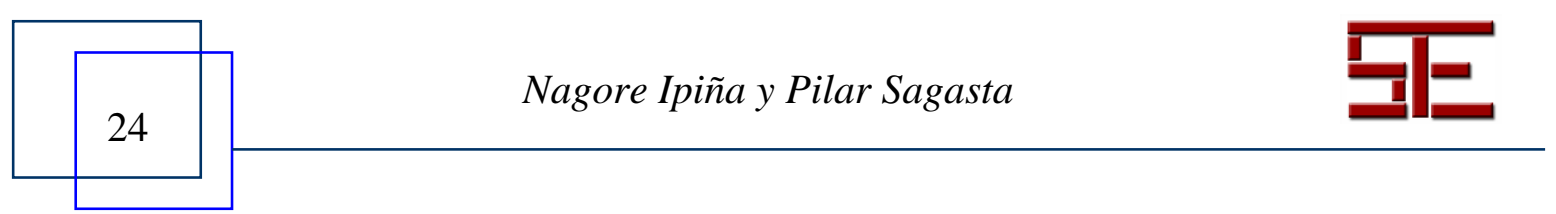




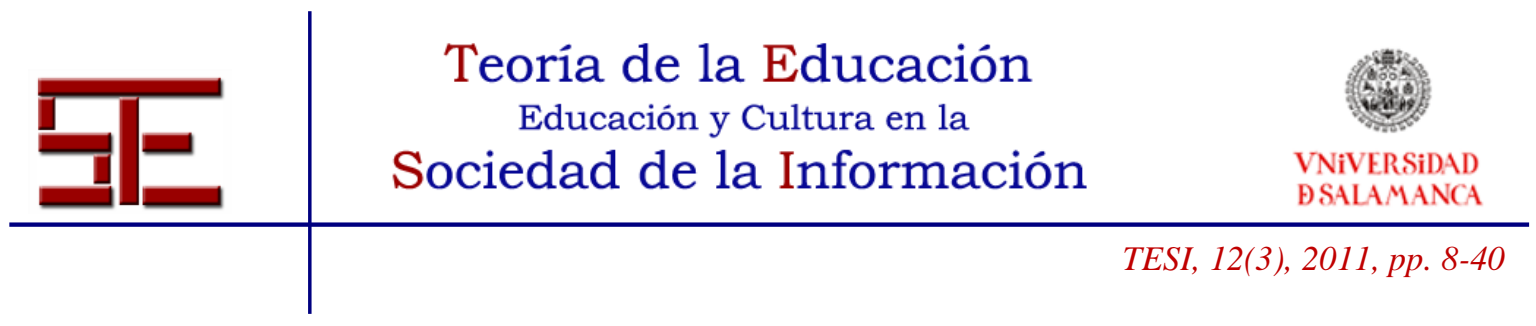

Tabla 7. Resumen de datos sociolingüísticos de la muestra

\begin{tabular}{|c|c|c|c|c|c|c|c|c|c|}
\hline \multicolumn{5}{|c|}{ Lengua materna } & \multicolumn{2}{|c|}{$\begin{array}{l}\text { Lengua } \\
\text { mayoritaria en el } \\
\text { ámbito } \\
\text { residencial }\end{array}$} & \multicolumn{3}{|c|}{$\begin{array}{l}\text { Modelo lingüístico } \\
\text { cursado } \\
\text { educación } \\
\text { obligatoria }\end{array}$} \\
\hline 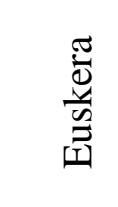 & 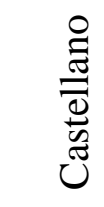 & $\begin{array}{l}\text { 节 } \\
\text { 完 }\end{array}$ & 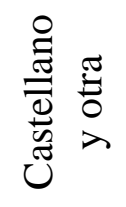 & 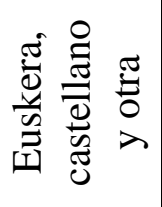 & 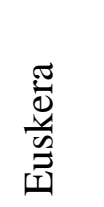 & 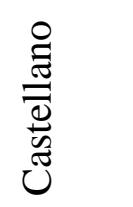 & A & B & $\mathrm{D}$ \\
\hline $58,2 \%$ & $20,7 \%$ & $20,1 \%$ & $0,5 \%$ & $0,5 \%$ & $56,7 \%$ & $43,3 \%$ & $2,2 \%$ & $4,5 \%$ & $93,3 \%$ \\
\hline
\end{tabular}

Como se puede observar en la tabla la lengua materna de la mayoría de los participantes $(78,3 \%)$ es el euskera o el euskera y el castellano, aunque provengan tanto de ámbitos mayoritariamente vasco-parlantes como castellano-parlantes. Cabe destacar el dato de que el 93,3\% de la muestra procede del modelo lingüístico D, y sólo el 6,7\% de los participantes del primer curso proceden del modelo A y B.

Una vez descrita la muestra de los participantes en términos generales y en términos lingüísticos y centrándonos en la materia descrita como base para este trabajo, las siguientes líneas describirán los datos de un cuestionario de satisfacción y de las reflexiones finales realizadas por los estudiantes al final de la materia y unas pequeñas conclusiones de dos de los siete tutores que impartieron la materia.

Como ya lo hemos mencionado, al final de la materia descrita los estudiantes respondieron a un cuestionario de satisfacción diseñado ad-hoc con el objetivo de valorar lo aprendido y reflexionar sobre posibles aspectos de mejora y realizaron una reflexión escrita sobre diferentes aspectos de la materia. De la misma materia se pidió a dos de los tutores que impartieron la materia que reflexionaran sobre ella en términos de desarrollo de competencias lingüísticas, competencias de contenido y utilización de la wiki como base del proyecto.

\section{1.- Datos obtenidos del cuestionario}

El cuestionario diseñado está formado por 32 ítems, 28 de los cuales responden a una naturaleza cuantitativa y 4 son de carácter cualitativo. En los primeros 28 ítems los estudiantes valoran en una escala del 1 al 10 cada una de las preguntas y en los últimos cuatro ítems cualitativos los participantes responden de manera escrita a posibles propuestas de mejora, factores que deberían ser eliminados, nuevos aspectos a añadir y por último, a aspectos que subrayarían positivamente de la materia.

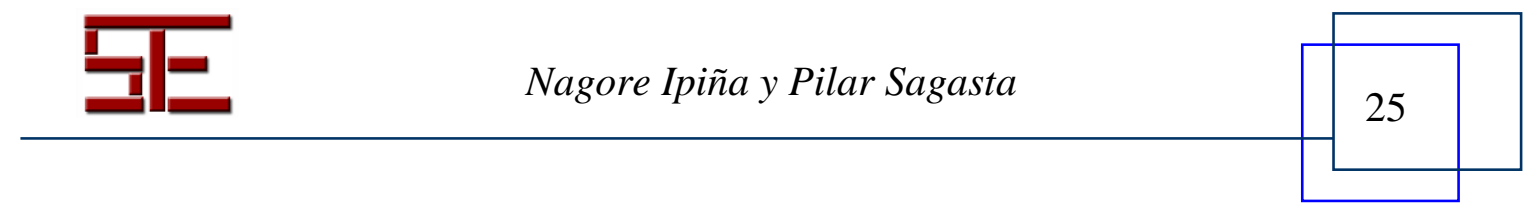




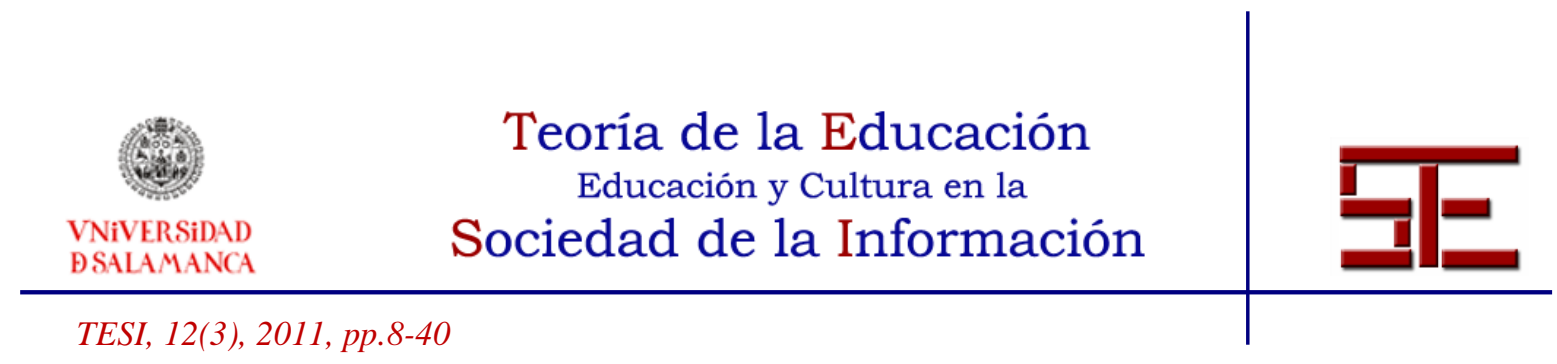

El cuestionario está dividido en siete bloques como muestra la siguiente tabla y como es también observable cada bloque se desglosa en los distintos ítems a responder. La tabla que se presenta posteriormente tiene como objetivo también esbozar la valoración general obtenida de los cuestionarios rellenados por los 184 participantes.

Tabla 8. Valoración cuantitativa obtenida de los cuestionarios

\begin{tabular}{|c|c|c|c|}
\hline \multicolumn{2}{|c|}{ Aspectos evaluados } & \multirow{2}{*}{$\begin{array}{l}\text { Criterios de evaluación } \\
\text { Participación individual }\end{array}$} & \multirow{2}{*}{$\begin{array}{l}\text { Valoración } \\
\text { general } \\
7,4\end{array}$} \\
\hline \multirow[t]{3}{*}{1} & \multirow[t]{3}{*}{ Participación } & & \\
\hline & & $\begin{array}{l}\text { Grado de desarrollo de competencias que } \\
\text { permite el diseño de la materia }\end{array}$ & 7,3 \\
\hline & & $\begin{array}{l}\text { Grado de participación en la evaluación que } \\
\text { permite el diseño de la materia }\end{array}$ & 7,4 \\
\hline \multirow[t]{3}{*}{2} & \multirow[t]{3}{*}{ Rol del tutor } & Cercanía mostrada por el tutor & 8,3 \\
\hline & & $\begin{array}{l}\text { El tutor ha ayudado a crear un ambiente } \\
\text { cómodo }\end{array}$ & 8,2 \\
\hline & & $\begin{array}{l}\text { El tutor ha ayuda en el proceso de } \\
\text { aprendizaje }\end{array}$ & 8,4 \\
\hline \multirow[t]{3}{*}{3} & \multirow[t]{3}{*}{ Tiempo } & $\begin{array}{l}\text { He andado cerca del tiempo previsto para las } \\
\text { horas no presenciales }\end{array}$ & 7,1 \\
\hline & & $\begin{array}{l}\text { He necesitado más tiempo del previsto para } \\
\text { las horas no presenciales }\end{array}$ & 5,8 \\
\hline & & $\begin{array}{l}\text { He necesitado menos tiempo del previsto } \\
\text { para las horas no presenciales }\end{array}$ & 3,9 \\
\hline \multirow[t]{2}{*}{4} & \multirow[t]{2}{*}{ Moodle } & $\begin{array}{l}\text { Grado de ayuda de la información de la } \\
\text { plataforma virtual }\end{array}$ & 7,2 \\
\hline & & $\begin{array}{l}\text { Grado en el que la plataforma ha facilitado } \\
\text { tu trabajo }\end{array}$ & 7,2 \\
\hline \multirow[t]{6}{*}{5} & \multirow[t]{6}{*}{ Materia } & $\begin{array}{l}\text { El orden de las diferentes secuencias } \\
\text { didácticas ha sido apropiado }\end{array}$ & 7,7 \\
\hline & & $\begin{array}{l}\text { Los temas propuestos han sido utilizables en } \\
\text { otras materias }\end{array}$ & 7,3 \\
\hline & & $\begin{array}{l}\text { Los criterios e instrumentos de evaluación } \\
\text { han sido apropiados }\end{array}$ & 7,5 \\
\hline & & Me he sentido a gusto con el tema & 7,6 \\
\hline & & Me he sentido bien en el grupo & 8,2 \\
\hline & & La materia me ha ayudado a desarrollar las & 7,7 \\
\hline & & Nagore Ipiña y Pilar Sagasta & \\
\hline
\end{tabular}




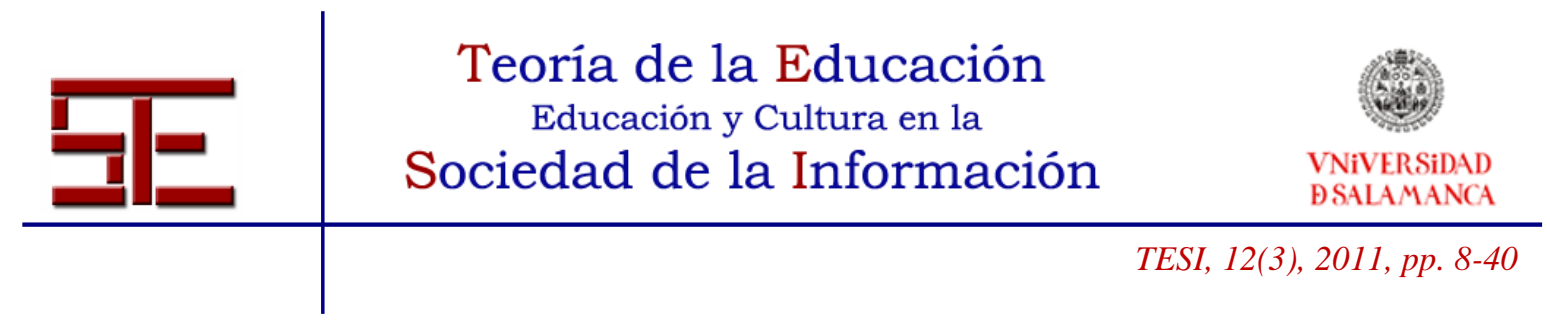

\begin{tabular}{|c|c|c|c|}
\hline & & competencias específicas & \\
\hline & & $\begin{array}{l}\text { La materia me ha ayudado a desarrollar las } \\
\text { competencias transversales }\end{array}$ & 7,7 \\
\hline \multirow[t]{9}{*}{6} & \multirow[t]{9}{*}{ Competencias } & $\begin{array}{l}\text { He aprendido sobre el sistema educativo de } \\
\text { la Comunidad Autónoma Vasca }\end{array}$ & 8,3 \\
\hline & & $\begin{array}{l}\text { He aprendido sobre sistemas educativos de } \\
\text { Europa como del resto del mundo }\end{array}$ & 7,7 \\
\hline & & $\begin{array}{l}\text { He aprendido sobre el plurilingüismo y la } \\
\text { multiculturalidad }\end{array}$ & 7,8 \\
\hline & & $\begin{array}{l}\text { He aprendido sobre la calidad en educación } \\
\text { y buenas prácticas }\end{array}$ & 7,5 \\
\hline & & $\begin{array}{l}\text { He aprendido a escribir textos expositivos en } \\
\text { inglés }\end{array}$ & 7,2 \\
\hline & & He aprendido a escribir informes en inglés & 7,2 \\
\hline & & $\begin{array}{l}\text { He aprendido mediante el proceso del } \\
\text { proyecto }\end{array}$ & 7,9 \\
\hline & & $\begin{array}{l}\text { He aprendido a utilizar la wiki como } \\
\text { herramienta para el trabajo colaborativo }\end{array}$ & 6 \\
\hline & & $\begin{array}{l}\text { He aprendido a realizar presentaciones } \\
\text { orales en inglés }\end{array}$ & 7,1 \\
\hline 7 & $\begin{array}{l}\text { Valoración general de } \\
\text { la materia }\end{array}$ & & 7,7 \\
\hline
\end{tabular}

Consideramos que no todos los ítems deben ser analizados con el fin de responder al objetivo de este trabajo, por lo cual nos centraremos en los referidos a las distintas competencias adquiridas por los estudiantes (sexto bloque). Para ello hemos desglosado la valoración general de estos ítems siguiendo a los 7 grupos en los que se ha impartido la materia. Cabe destacar que los primeros tres grupos (EI T1, EI T2 y EI T3) son grupos de la especialidad de Educación Infantil y los últimos cuatro (EP T1, EP T2, EP T3 y EP T4) de Educación Primaria.

Tabla 9- Desglose de la valoración de competencias desarrolladas por grupo

\begin{tabular}{|l|l|l|l|l|l|l|l|l|}
\hline & $\begin{array}{l}\text { EI } \\
\text { T1 }\end{array}$ & $\begin{array}{l}\text { EI } \\
\text { T2 }\end{array}$ & $\begin{array}{l}\text { EI } \\
\text { T3 }\end{array}$ & $\begin{array}{l}\text { EP } \\
\text { T1 }\end{array}$ & $\begin{array}{l}\text { EP } \\
\text { T2 }\end{array}$ & $\begin{array}{l}\text { EP } \\
\text { T3 }\end{array}$ & $\begin{array}{l}\text { EP } \\
\text { T4 }\end{array}$ & media \\
\hline $\begin{array}{l}\text { 1.-He aprendido sobre } \\
\text { el sistema educativo de } \\
\text { la }\end{array}$ & 7,9 & 8,7 & 9,0 & 8,1 & 7,5 & 8,5 & 8,3 & 8,3 \\
\hline
\end{tabular}

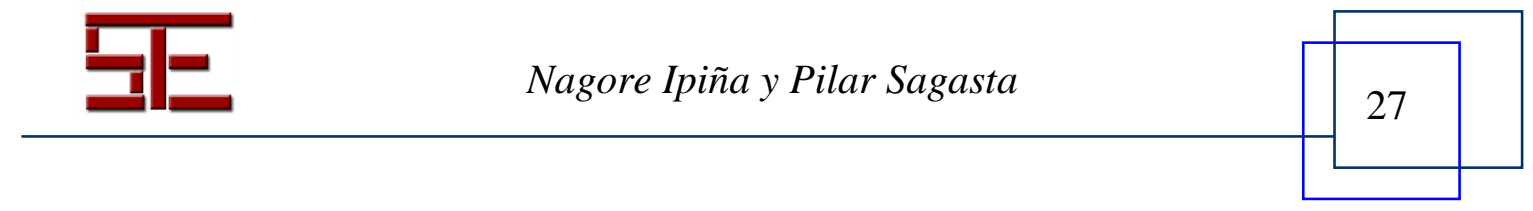




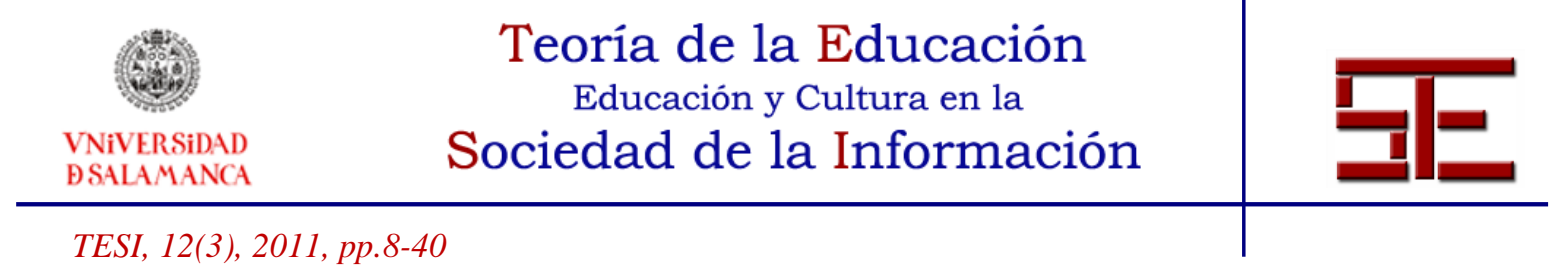

\begin{tabular}{|l|l|l|l|l|l|l|l|l|}
\hline Autónoma Vasca & & & & & & & & \\
\hline $\begin{array}{l}\text { 2.-He aprendido sobre } \\
\text { sistemas educativos de } \\
\text { Europa como del resto } \\
\text { del mundo }\end{array}$ & 7,6 & 7,9 & 8,4 & 7,8 & 7,0 & 7,4 & 7,8 & 7,7 \\
\hline $\begin{array}{l}\text { 3.-He aprendido sobre } \\
\text { el plurilingüismo y la } \\
\text { multiculturalidad }\end{array}$ & 7,6 & 8,1 & 8,3 & 7,7 & 7,2 & 7,8 & 8,0 & 7,8 \\
\hline $\begin{array}{l}4 .-H e \text { aprendido sobre } \\
\text { la calidad en educación } \\
\text { y buenas prácticas }\end{array}$ & 7,3 & 7,9 & 8,3 & 7,4 & 6,8 & 7,5 & 7,6 & 7,5 \\
\hline $\begin{array}{l}\text { 5.-He aprendido a } \\
\text { escribir textos } \\
\text { expositivos en inglés }\end{array}$ & 7,0 & 7,3 & 7,8 & 7,4 & 6,5 & 6,9 & 7,7 & 7,2 \\
\hline $\begin{array}{l}\text { 6.-He aprendido a } \\
\text { escribir informes en } \\
\text { inglés }\end{array}$ & 6,9 & 7,3 & 7,7 & 7,3 & 6,7 & 6,8 & 7,4 & 7,2 \\
\hline $\begin{array}{l}7 .-H e \text { aprendido } \\
\text { mediante el proceso del } \\
\text { proyecto }\end{array}$ & 8,0 & 8,0 & 8,6 & 8,1 & 7,4 & 7,5 & 7,8 & 7,9 \\
\hline $\begin{array}{l}\text { 8.-He aprendido a a } \\
\text { utilizar la wiki como } \\
\text { herramienta para el } \\
\text { trabajo colaborativo }\end{array}$ & 2,7 & 5,5 & 6,9 & 7,4 & 6,3 & 5,6 & 7,6 & 6,0 \\
\hline $\begin{array}{l}\text { 9.-He aprendido a } \\
\text { realizar presentaciones } \\
\text { orales en inglés }\end{array}$ & 6,9 & 7,2 & 7,8 & 6,4 & 6,8 & 7,1 & 7,3 & 7,1 \\
\hline
\end{tabular}

Como se puede observar en la tabla anterior los datos obtenidos de los cuestionarios muestran que los participantes reconocen haber adquirido tanto competencias específicas relacionadas con el contenido como con el idioma, situándose la media de la mayoría de ellos en torno a 7,5 puntos. Cabe destacar la elevada puntuación que obtienen los ítems relativos al aprendizaje del sistema educativo vasco ( 8,3 sobre 10$)$ como el relativo al tema de plurilingüismo y multiculturalidad $(7,8)$ en lo que al contenido se refiere y el relativo al aprendizaje mediante el proyecto $(7,9)$. En cuanto a las competencias lingüísticas se observa que todos los ítems (ítems 5, 6 y 9) rondan una puntuación que supera el 7.

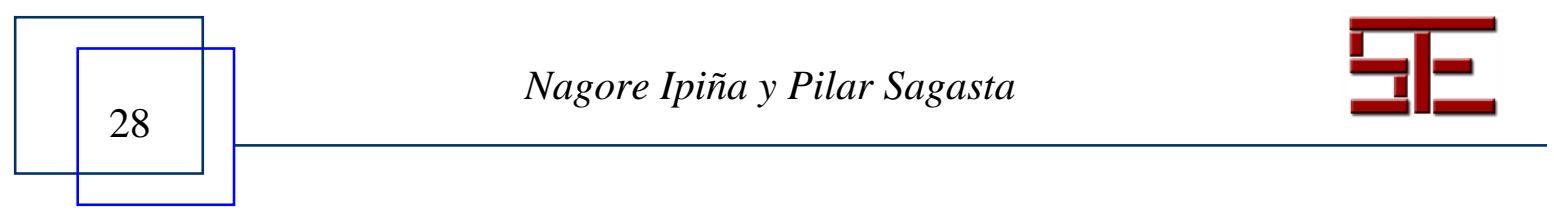




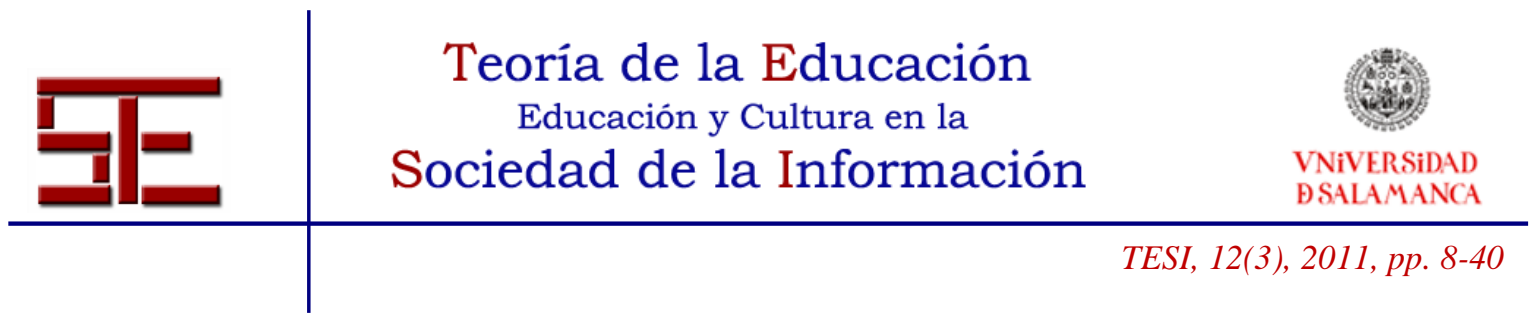

Por otro lado, y centrando la atención en las nuevas tecnologías, la satisfacción media de los estudiantes es de 6 puntos, considerablemente más baja que en el resto de los ítems. Más aun, la diferencia existente en la satisfacción entre los grupos en torno a este aspecto es considerablemente llamativa. Como puede observarse en la tabla anterior la puntuación varía de un 2,7 a un 7,6, lo cual nos lleva a reflexionar sobre aspectos relativos al profesorado además de al alumnado.

En cuanto a los aspectos cualitativos, la mayoría de los estudiantes coinciden en subrayar el interés que ha suscitado esta nueva experiencia y en la pertinencia de los temas desarrollados en la materia para su futuro. También mencionan que el proyecto les ha ayudado a contextualizar lo trabajado y a acercarse a la realidad.

Llama la atención que la wiki sea una de las opciones más citadas en las preguntas cualitativas. En estas últimas la wiki se sitúa en extremos opuestos; es decir, mientras que algunos estudiantes mencionan que la wiki es lo que querrían resaltar de la materia otros lo consideran un aspecto a eliminar o cuanto menos a revisar. Otro aspecto considerado por muchos participantes a eliminar son las lecturas requeridas y el número de textos escritos a desarrollar.

\section{2.- Reflexiones escritas de los participantes}

Con el fin de recolectar información escrita y evidencias cualitativas para la mejora de la materia se requirió de los estudiantes una sobre los siguientes aspectos: el contenido y su aprendizaje, la metodología, el proyecto y sus sentimientos.

Cabe destacar que todos los estudiantes que realizaron la reflexión (182) coincidieron en destacar la mejoría lingüística junto con el aprendizaje de contenidos. El siguiente e extracto muestra la reflexión de uno de los estudiantes de Educación Primaria ${ }^{1}$.

Cuando empecé mi nivel de inglés no era bueno y reconozco que tenía miedo cuando nos dijeron que íbamos a dar una materia en inglés. Ahora que ha pasado el tiempo veo que mi nivel de inglés escrito y sobre todo oral ha mejorado y además he aprendido muchas cosas sobre los diferentes sistemas educativos del mundo; el plurilingüismo y la multiculturalidad y la calidad. ST1(EP).

Con respecto a la metodología utilizada, trabajo en pequeños grupos, y a las actividades desarrolladas, lecturas, presentaciones y pequeños proyectos, etc., los estudiantes

\footnotetext{
${ }^{1}$ Todos los extractos que se mostrarán en este apartado han sido traducidos del inglés al castellano por las autoras de este texto.
}

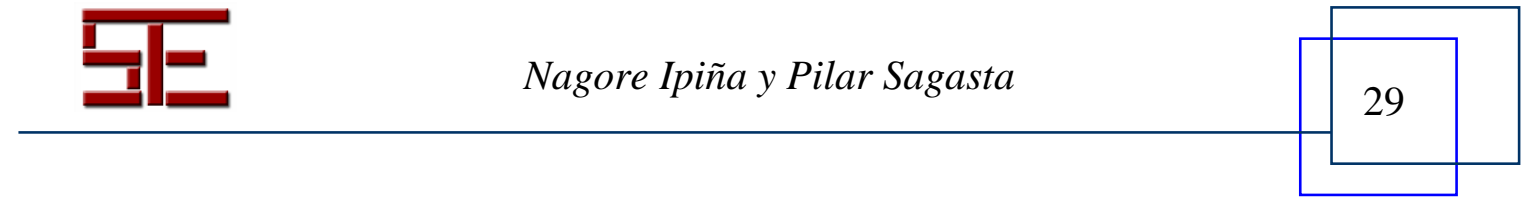




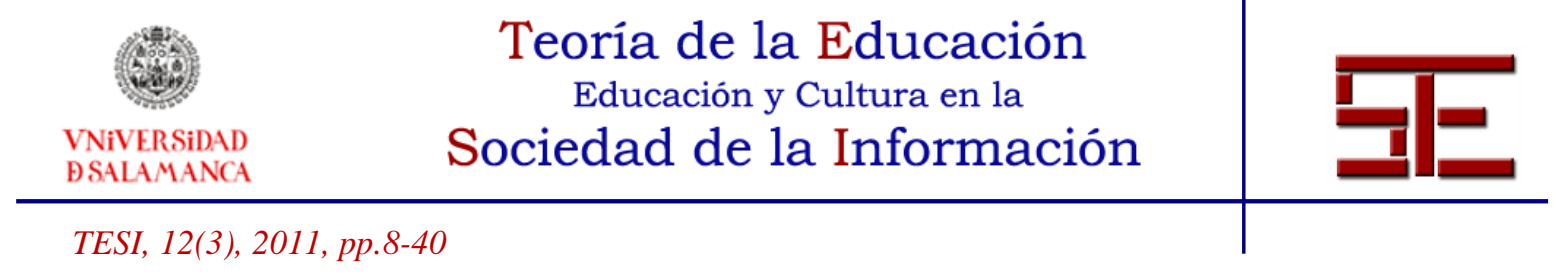

también mostraron una conciencia bastante clara de que la metodología de trabajo les había ayudado en la mejora de las competencias.

Yo creo que he aprendido mucho porque no hemos estado escuchando y tomando apuntes sino que trabajando con mis compañeros me he esforzado más en aprender. ST2 (EP).

Nunca había trabajado así en una clase hasta llegar aquí y la verdad es que me siento a gusto de esta manera, aprendo más y mejor. ST3 (EP)...

Como hemos expuesto en el apartado anterior los estudiantes consideran que han aprendido mucho durante el proceso de la realización del proyecto. Sus reflexiones escritas también afianzan lo cuantitativamente descrito.

Trabajando en el proyecto he aprendido más de lo que hubiera imaginado. Cuando presentamos el proyecto delante de toda la clase sentí que sabía lo que decía y por qué lo decía. Hemos trabajado duro, han sido muchas horas para desarrollar el informe y preparar la presentación, pero investigando en diferentes páginas web he aprendido mucho. ST 4 (EP).

Al principio, entre el idioma y que no entendía muy bien lo que teníamos que hacer, era desesperante y encima la wiki, otra cosa más. Pero luego, aunque hemos tenido algunos problemas, ha sido una experiencia muy enriquecedora. ST 5 (EP).

Querríamos mencionar que en lo relativo al uso de la wiki proyecto los estudiantes muestran las mismas afirmaciones que hemos mencionado. Algunos valoran y escriben que ha sido muy positivo mientras otros siguen sin entender su función ni su utilización.

No sé por qué hemos tenido que utilizar una wiki. Nosotros hemos preferido quedar y trabajar en grupo como lo hemos hecho hasta ahora. ST 6 (EP).

Me ha encantado la idea de trabajar en el proyecto con mis compañeros por medio de la wiki. Como era bastante dificil juntarnos para trabajar comenzamos a utilizar la wiki desde el principio y nos ha ayudado mucho. ST7 (EP).

Los sentimientos expuestos por los estudiantes también son positivos, incluso algunos de ellos refuerzan la ayuda del tutor en esta experiencia.

Aunque al principio sentí cierta ansiedad por la situación, con la ayuda del tutor y el ambiente que se ha creado en el grupo, me he sentido estupendamente; y al igual que mis compañeros he aprendido y me he divertido. ST 8 (EP).

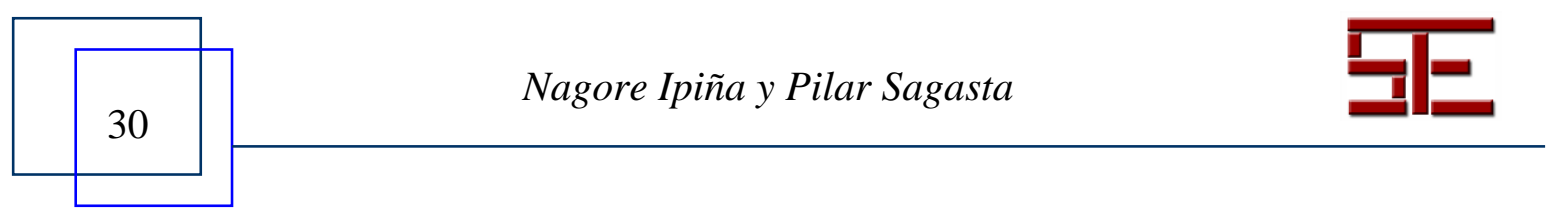




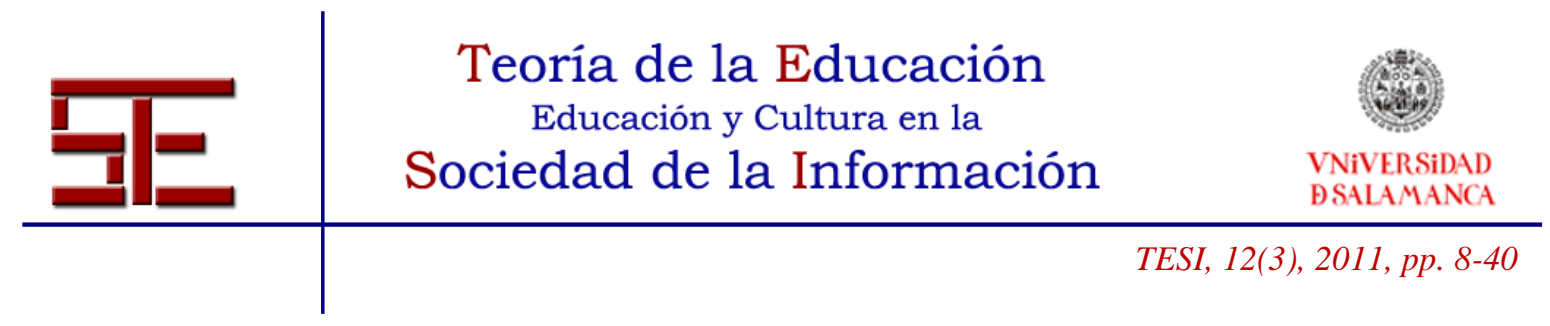

Como se puede observar estas evidencias no distan mucho de los datos obtenidos de los cuestionarios. Los estudiantes muestran opiniones coherentes a lo respondido cuantitativamente, pero aun así consideramos necesario conocer también las opiniones de los tutores ya que son parte de la experiencia y ayudan a la reflexión pedagógica para la mejora.

\section{3.- Reflexiones de los tutores}

Una vez obtenidos todos los datos de los cuestionarios de satisfacción y las reflexiones escritas, hemos recogido el testimonio de dos de los siete tutores que participaron en esta experiencia. Los siguientes extractos son comentarios de dos tutores de los grupos de Educación Primaria, T2 y T4 respectivamente. En ambos casos se hace patente la concordancia que presentan con lo mencionado por los estudiantes sobre las diferentes competencias relativas tanto a los contenidos como a las competencias lingüísticas desarrolladas. Uno de los tutores subraya también la preocupación por la utilización de la wiki y su utilización.

En mi opinión, los estudiantes que han cursado esta materia han avanzado tanto a nivel de contenidos como a nivel de competencia lingüística. El hecho de tener que utilizar la lengua para expresar los contenidos relacionados con la materia, han ayudado al estudiante a ver la lengua y su utilidad de una forma diferente, encontrándole mayor sentido que el que a menudo le encontraba hasta el momento. Además, la necesidad de expresar contenidos mueve al aprendiz a avanzar en el uso lingüístico. (EP $\mathrm{T} 2)$.

Yo creo que los estudiantes han aprendido mucho y más aún, que son conscientes de ello. Aunque hay muchos aspectos que debemos mejorar es importante que seamos conscientes del cambio de actitud que hemos conseguido en la mayoría de los aspectos. Me acuerdo del primer día cuando los estudiantes miraban, porque no creo que escucharan, con cara de susto lo que les decíamos y como han participado activamente en la materia. Aún así creo que no hemos conseguido cambiar algunos de sus hábitos de trabajo. Utilizamos la wiki como un recurso para el trabajo colaborativo pero la mayoría no han entendido su filosofía; siguen repartiendo el trabajo y juntándolo el último día. (EP T4).

Con los distintos datos obtenidos tanto cuantitativamente como cualitativamente el siguiente y último apartado presenta las conclusiones relativas a los distintos aspectos desarrollados en este trabajo.

\section{8.- CONCLUSIONES}

Este apartado presenta, primeramente, algunas conclusiones relativas al desarrollo de la competencia plurilingüe en contextos de lengua minoritaria $\mathrm{y}$, en segundo lugar

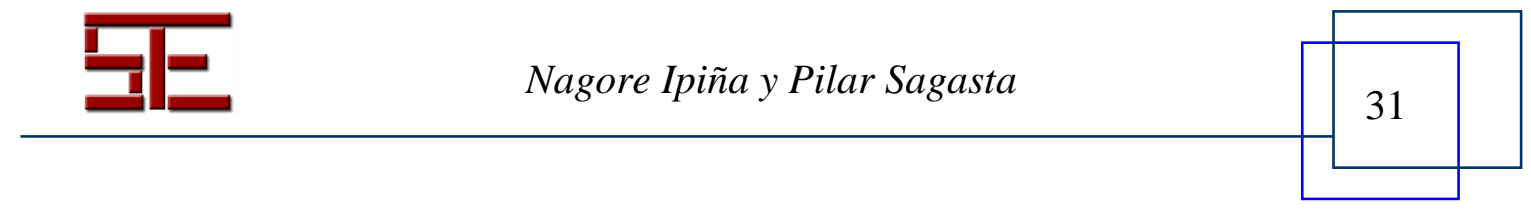




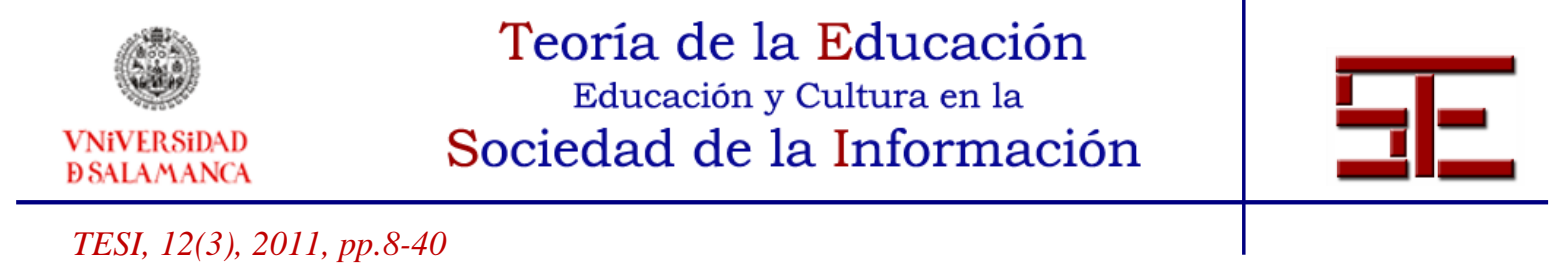

conclusiones relativas a la utilización de la wiki y su contribución al desarrollo de dicha competencia.

El desarrollo de la competencia plurilingüe es un fenómeno complejo donde intervienen numerosas variables que a su vez interactúan entre ellas. En el plan de educación plurilingüe que hemos diseñado hemos seleccionado una serie de variables que consideramos importantes para lograr los objetivos que nos hemos propuesto. Pero probablemente influyen también otros aspectos que no hemos considerado, como por ejemplo las representaciones de los tutores en relación con la competencia plurilingüe y con el desarrollo de la misma.

Otro tema a destacar es la coordinación del equipo docente que participa en los grados de Educación Infantil y Primaria. Un plan de educación plurilingüe requiere la participación de todo el equipo docente que toma parte en la titulación. Y es necesario un buen conocimiento de todas las materias que se imparten en el currículum, porque es la materia la que define las necesidades lingüísticas de los estudiantes. Por lo tanto, se precisa una buena coordinación entre los tutores de las materias y los especialistas en lenguas. No siempre es fácil, porque a veces los tutores de las materias no atribuyen a la lengua su importancia como herramienta de mediación en la construcción de significados de dichas materias.

Otro reto importante es la competencia pedagógica que se requiere para que el aprendizaje integrado de áreas de conocimiento y lenguas tenga éxito. Hay tutores que inciden más en las competencias relacionadas con el área en cuestión y otros ponen un mayor énfasis en los aspectos lingüísticos, y este es un fenómeno que se repite en diversos contextos (Dalton-Puffer, 2007). Además los tutores partimos de una formación tradicional y no interdisciplinar, estamos preparados para trabajar nuestra disciplina, pero no para integrar varias disciplinas. Es necesario, por tanto, un buen plan de formación docente para el aprendizaje integrado.

En lo que a la utilización de las aplicaciones 2.0, la wiki en este caso, se refiere y coincidiendo con Cole (2009), que no todas las experiencias de utilización de wiki son satisfactorias, consideramos necesaria una reflexión en torno a los factores implicados en el éxito del uso pedagógico de la wiki para el trabajo colaborativo. Las diferencias significativas entre los grupos en cuanto a la utilización de la wiki nos llevan a considerar y revisar, no sólo la formación y el perfil tecnológico de los docentes, sino también la importancia de la actitud de los tutores hacia estas tecnologías (Guo y Stevens, 2011).

Por lo tanto, como conclusión final de todos los aspectos abordados en este trabajo, consideramos que la formación, tanto de docentes como de estudiantes, es la pieza clave

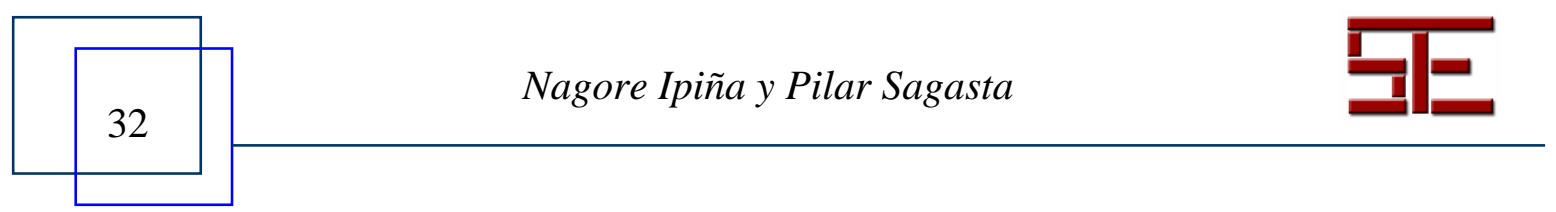




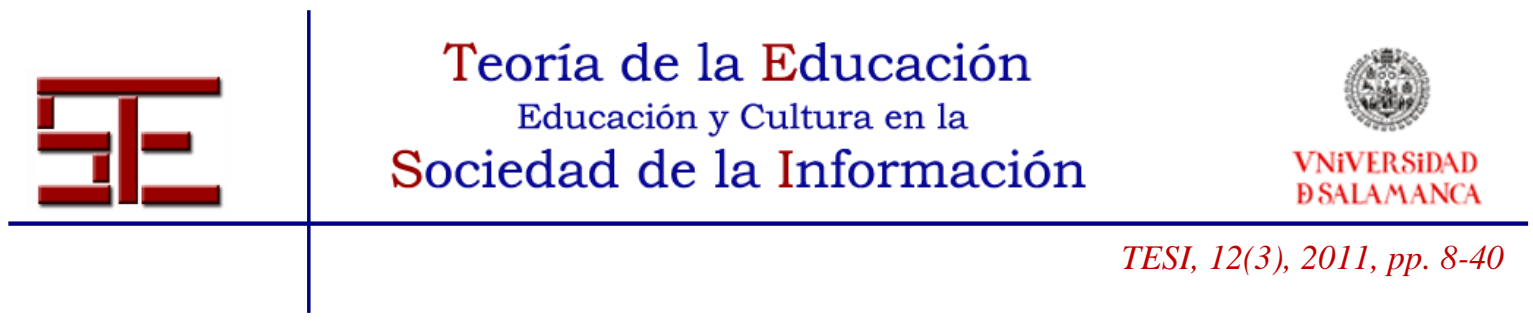

para comenzar a integrar los diversos campos interdisciplinares de una forma coherente y significativa en la Sociedad del Conocimiento.

\section{9.- BIBLIOGRAFÍA}

Area, M. (2009). Las wikis en mi experiencia docente. Del diccionario de la asignatura al diario de clase. Red U - Revista de Docencia Universitaria. Número monográfico IV. Número especial dedicado a Wiki y educación superior en España (en coedición con Revista de Educación a Distancia -RED). 15 de diciembre de 2009. Consultado el 20/03/2010 en http://www.um.es/ead/Red_U/m4/.

Augar, N., Raitman, R. y Zhou, W. (2004). Teaching and learning online with wikis. En R. Atkinson, C. McBeath, D. Jonas-Dwyer \& R. Phillips (Ed), Beyond the comfort zone: Proceedings of the 21st ASCILITE Conference. (95-104). Consultado el 18/05/2011 en: http://www.ascilite.org.au/conferences/perth04/procs/augar.html

Baetens B. (2001). The Past Decade and the Next Millennium. En D. Marsh, A. Majtels y A. Hartiala. Profiling CLIL Classsrooms. Findland: Universty of Jyväskulä.

Barberá, E. (2009). Filosofía wiki: el compromiso de las soluciones. RED-Revista de Educación a distancia. Número monográfico X. Número especial dedicado a Wiki y educación superior en España (en coedición con $\operatorname{Red}-U$ ). 15 de diciembre de 2009. Consultado el 18/05/2011 en http://www.um.es/ead/red/M10/.

Barton, M. (2004). Embrace the wiki way! [Versión electrónica], May, 21, 2004. Consultado el 12/08/2011 en http://www.mattbarton.net/tikiwiki/tikiread_article.php?articleId $=4$.

Bernaus, M. (1996). Introduction of a third language from kindergarten. How it can affect L1 and L2 acquisition. APAC of news. Barcelona.

Bower, M., Woo, K., Roberts, M. \& Watters, P. A. (2006). Wiki pedagogy - A tale of two wikis. Presentado en: 7th International Conference on Information Technology Based Higher Education and Training (ITHET 06), Sydney, Australia. Consultado el 13/08/2011 en http://mq.academia.edu/KarenWoo/Papers/475244/Wiki_pedagogyA_tale_of_two_wikis.

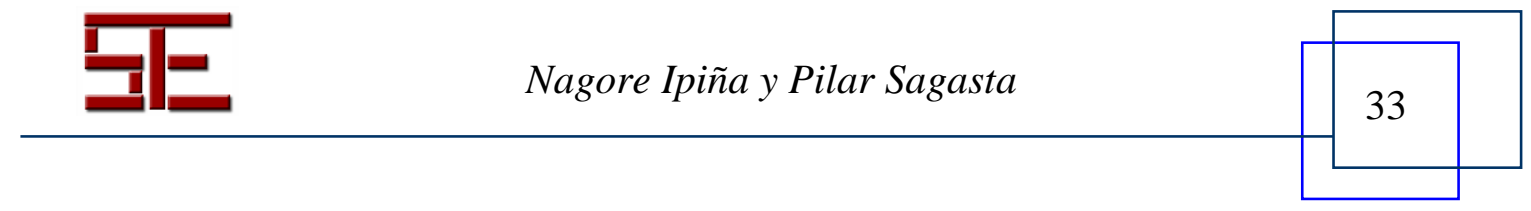




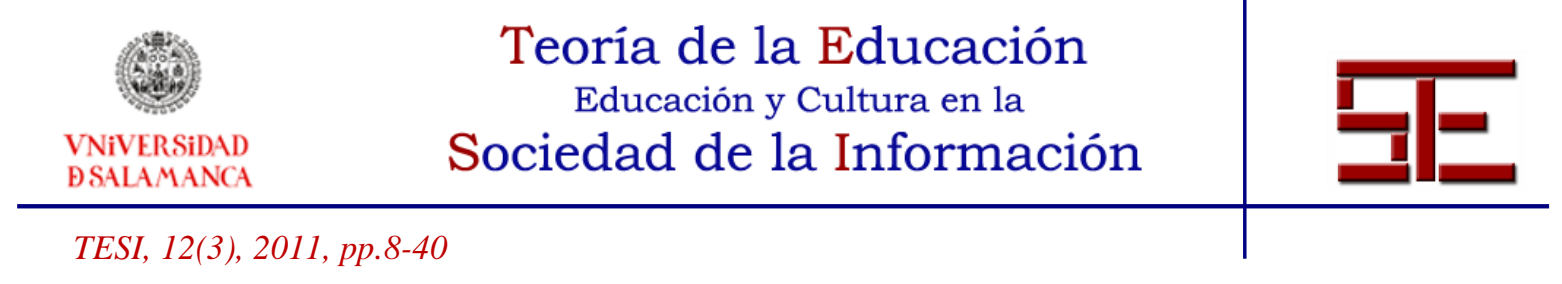

Carrasquillo, A. y Rodríguez, V. (1996). Language minority students in the mainstream classroom. Clevedon: Multilingual Matters.

Cenoz, J. (1992). Enseñanza-aprendizaje del inglés como L2 o L3. Tesis Doctorales. Universidad del País Vasco. Facultad de Filosofía y Ciencias de la Educación.

- (1998). Multilingual educación in the Basque Country. En J. Cenoz y F. Genesee (Ed), Beyond bilingualism. Multilingualism and multicultural education. (175-191). Clevedon: Multilingual Matters.

Cenoz, J. y Genesee, F. (1998). Psycholinguistic perspectives on multilingual and multicultural education. En J. Cenoz y F. Genesee (Eds.), Beyond bilingualism: multilingualism and multilingual education. (16-32). Clevedon: Multilingual Matters.

Chao, J. (2007). Student project collaboration using Wikis. Proceedings of the 20th Conference on Software Engineering Education and Training (CSEE\&T 2007), Dublin, Ireland: July 3-5.

Chen, H. L., Cannon, D., Gabrio, J. Leifer, L. Toye, G. \& Bailey, T. (2005). Using wikis and weblogs to support reflective learning in an introductory engineering design course. Proceedings of the 2005 American Society for Engineering Education Annual Conference \& Exposition, Portland, Oregon: June 12-15. Consultado el 28/09/2006 en: http://riee.stevens.edu/fileadmin/riee/pdf/ASEE2005_Paper_Wikis_and_Weblogs.pdf.

Coelho, E. (2005). Enseñar y aprender en escuelas multiculturales. Barcelona: Horsori.

Comisión de las Comunidades Europeas (2008). Multilingüismo: una ventaja para Europa y un compromiso compartido. Bruselas, [en línea] http://ec.europa.eu/education/languages/pdf/com/2008_0566_es.pdf [Consultado el 1 Agosto 2011].

Cole, M. (2009). Using wiki technology to support student engagement: Lessons from the trenches. Computers \& Education, 52, 141-146.

Cook, V. (1995). Multi-competence and the learning of many languages. Language, Culture and Curriculum, 8, 93-98.

Coyle, D., Hood, P. y Marsh, D. (2010). CLIL. Content and Language Integrated Learning. Cambridge: Cambridge University Press.

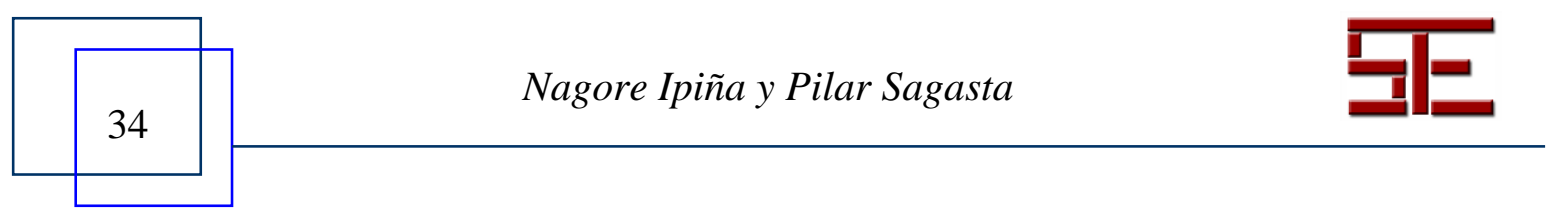




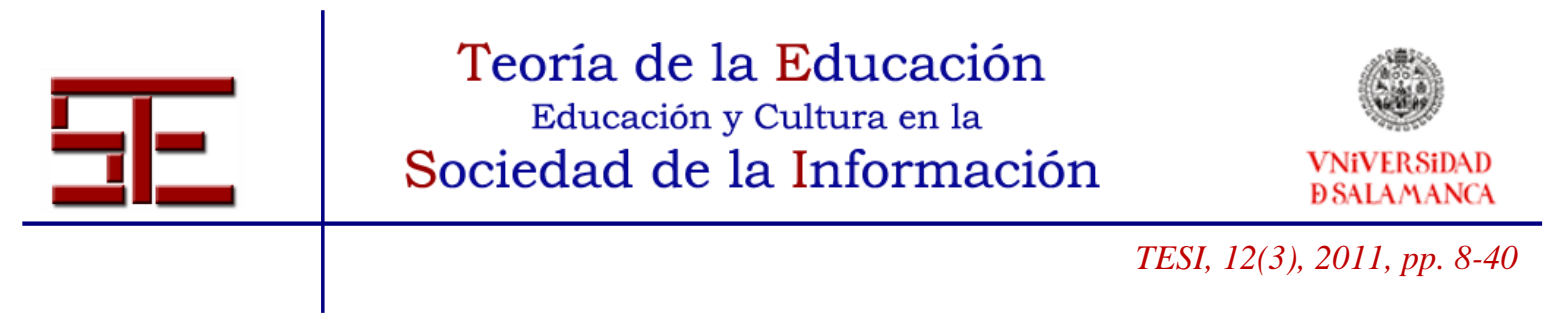

Cummins, J. (1983). Interdependencia lingüística y desarrollo educativo de los niños bilingües. Infancia y Aprendizaje, 21, 37-61.

- (2005). La Hipótesis de la Interdependencia 25 años después: la investigación actual y sus implicaciones para la educación bilingüe. En D. Lasagabaster y J. M. Sierra, Multilingüismo y multiculturalismo en la escuela. Barcelona: ICEHORSORI.

Dalton-Puffer, C. (2007). Discourse in Context and language Integrated Learning (CLIL) classrooms. Amsterdam: John Benjamins Publishing Company.

Davidson, M. (2008). Using focus groups to learn about my wiki. Computers in Libraries, 28 (1), 16-19, 47-48.

Davis, J. (2004). Wiki Brainstorming and Problems with Wiki Based Collaboration. Consultado el 20/07/2011 en: http://citeseerx.ist.psu.edu/viewdoc/download?doi=10.1.1.106.2987\&rep=rep1\&type=p df.

Echevarria, J., Vogt, M. y Short, D. J. (2004 2a ed.). Making content comprehensible for English learners. The SIOP model. Boston: Pearson Education Inc.

Elorza, I. y Muñoz, I. (2008). Promoting the Minority Language through integrated plurilingual language planning: the case of Ikastolas. En J. Cenoz, Teaching through Basque. (pp. 85-101).

Espi, M. J. (1994). Adquisición de segundas lenguas en la escuela. El papel de lo psicosocial. En I. Idiazabal y A. Kaifer (Ed.), Eficacia educativa y enseñanza bilingüe en el País Vasco. Colección Tesis Doctorales. Instituto Vasco de Administración Pública.

Eustat (2011).

http://www.hezkuntza.ejgv.euskadi.net/r43-

573/eu/contenidos/informacion/dia4/eu_2011_12/adjuntos/EAE_ereduka_INFPRIM.pdf [Consultado el 2 Agosto de 2011]

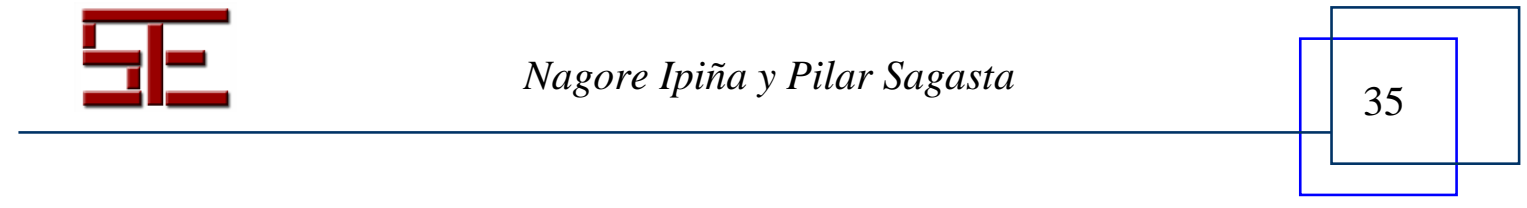




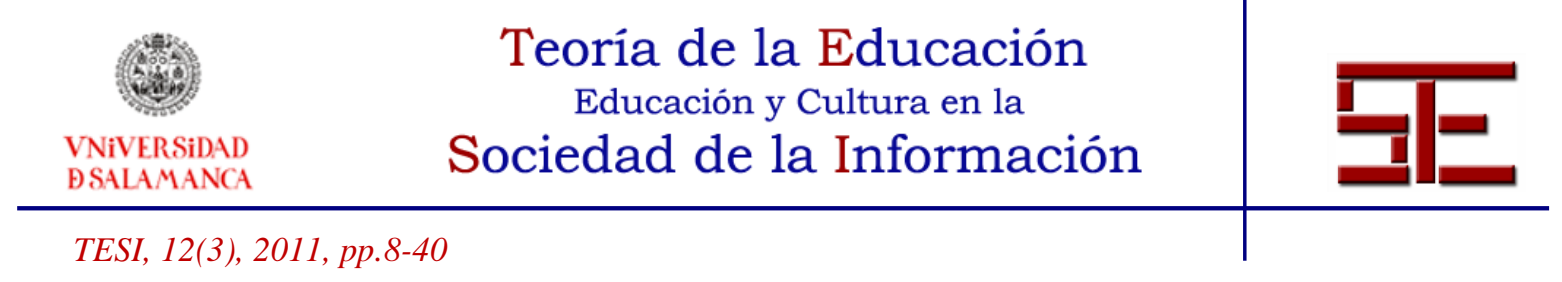

Evans, P. (2006). The wiki factor. BizEd, January/February, 28-32. Consultado el 19/02/2010 en http://www.aacsb.edu/publications/Archives/JanFeb06/p28-33.pdf.

Francisco Amat, A. (2011). Usando la web 2.0 para informarse e informar. Una experiencia en educación superior. En Hernández Serrano, M. J. y Fuentes Agustí, M. (Coords.). La red como recurso de información en educación. Revista Teoría de la Educación: Educación y Cultura en la Sociedad de la Información. vol. 12, no 1. Universidad de Salamanca, pp. 145-166 . Consultado el 5/08/2011 en:

http://campus.usal.es/ revistas_trabajo/index.php/revistatesi/article/view/7827/7854.

Gardner, R. C. (1985). Social Psychology and Second language Learning: The role of attitudes and motivation. London: Edward Arnold.

Gardner, N. y Zalbide, M. (2005). Basque Acquisition Planning. International Journal of the Sociology of Language, 174, 55-72.

Gimeno, A. y García, J. (2009). Wikis y el nuevo estudiante de lenguas extranjeras. Red U - Revista de Docencia Universitaria. Número Monográfico V. Número especial dedicado a WIKI y educación superior en España (II parte), en coedición con Revista de Educación a Distancia (RED), 31 de diciembre de 2009. Consultado el 18/05/2010 en http://www.um.es/ead/Red_U/m5/.

Grosjean, F. (1992). Another view of bilingualism. En R. J. Harris (Ed.), Cognitive Processing in Bilinguals. Amsterdam: North Holland. (pp. 51-62).

Guo, Z. \& Stevens, K. J. (2011). Factors influencing perceived usefulness of wikis for group collaborative learning by first year students. Australasian Journal of Educational Technology, 27 (2), 221-242. Consultado el 12/08/2011 en http://www.ascilite.org.au/ajet/ajet27/guo.html.

Guzdial, M. (1999). Collaborative websites to support an authoring community on the Web. Journal of the Learning Sciences.

Hazari, S., North, A. y Moreland, D. (2009). Investigating pedagogical value of Wiki technology. Journal of Information Systems Education, 20 (2), 187-198.

ISEI-IVEI (2005). Nivel B2 de euskera. Al finalizar la enseñanza obligatoria (4 $\left.{ }^{\circ} \mathrm{ESO}\right)$. www.isei-ivei.net.

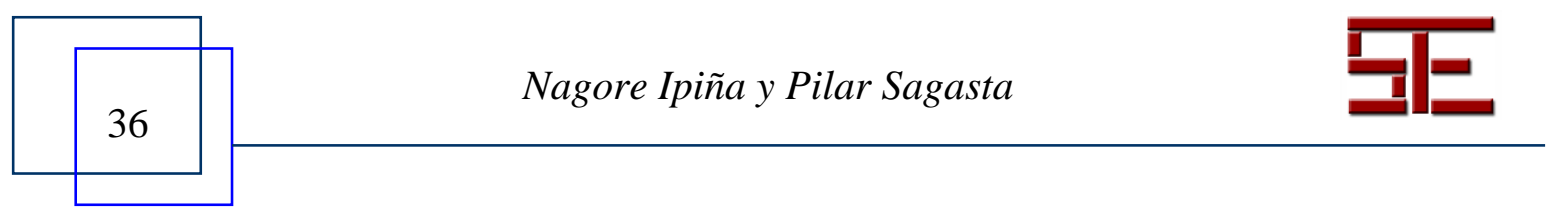




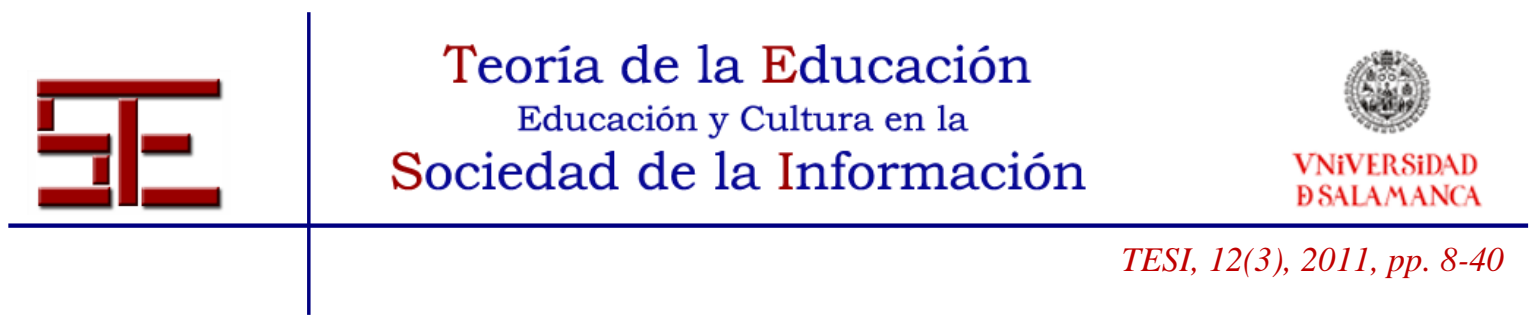

- (2007). Alumnado trilingüe en secundaria: una nueva realidad. www.iseiivei.net

Jessner, U. (1997). Towards a dynamic view of multilingualism. En M. Pütz (Ed.), Language Choices? Conditions, Constraints and Consequences. (pp. 17-30). Amsterdam: Benjamins.

Lamb, B. (2004). Open Spaces: Wikis, Ready or Not. EDUCAUSE Review, 39(5), September/October, 36-48. Consultado el 8/09/2009 en http://www.educause.edu/EDUCAUSE+Review/EDUCAUSEReviewMagazineVolume 39/WideOpenSpacesWikisReadyorNot/157925.

Lambert, W. E. (1979). Language as a factor in intergroup relation. En Giles y St Clair (Ed). Language and social psychology. Oxford: Basil Blackwell.

Laplante, B. (1996). Stratégies pédagogiques et représentation de la langue dans l'enseignement des sciences en immersion française. The Canadian Modern Language Review, 52 (3), 440-463.

- (2000). Apprendre en sciencies, c'est apprendre á parler sciences: des élèves de l'immersion nous parlent des réactions chimiques. The Canadian Modern Language Review, 57, 2, 245-271.

- (2005). Aprendre a parlar ciènces en la immersió: implicacions en les altres matèries. Immersió Lingüística. Revista d'Ensenyament Integrat de Llengües $i$ Continguts, 7, 8-20.

Lasagabaster, D. (1998a). Creatividad y conciencia metalingüística: incidencia en el aprendizaje del inglés como L3. Tesi Doktoralen Saila. Euskal Herriko Unibertsitatea. Ingeles eta Aleman Filologiaren Departamentua.

- (2003). Trilingüismo en la Enseñanza: Actitudes hacia la lengua minoritaria, mayoritaria y extranjera. Lleida: Editorial Milenio.

- (2005). Attitudes towards Basque, Spanish and English: An Study of the Most Influencial Variables. Journal of Multicultural and Multilingual Matters, 26, 4.

Leuf, B. \& Cunnignham, W. (2001). The wiki way: Quick collaboration on the web. Boston: Addison Wesley.

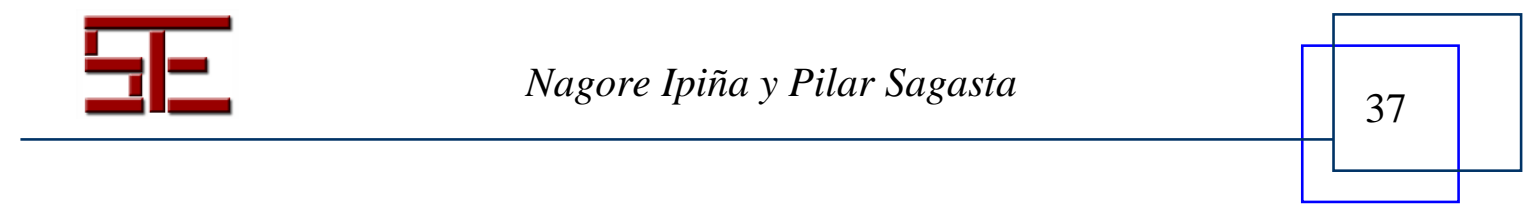




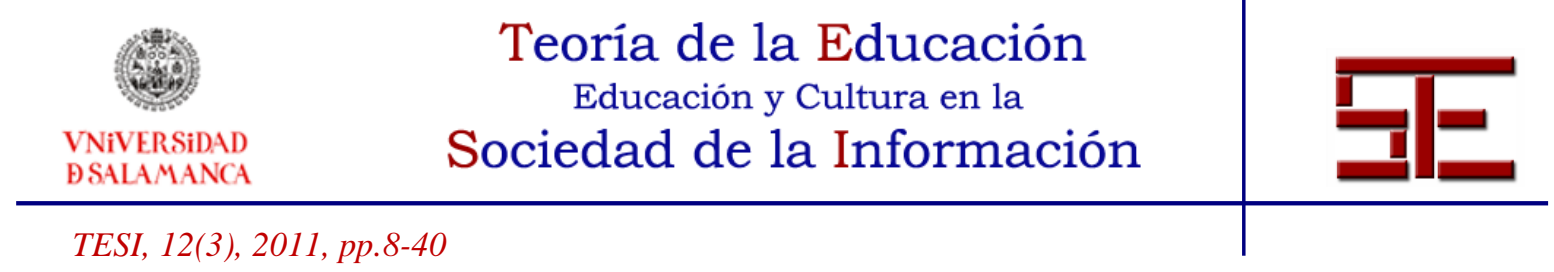

Madariaga, J. Ma . (1994). El papel de las actitudes en la educación bilingüe. Estudio comparativo realizado según los modelos lingüísticos A y D. En I. Idiazabal y A. Kaifer (Ed.), Eficacia educativa y enseñanza bilingüe en el País Vasco. Colección Tesis Doctorales. Instituto Vasco de Administración Pública.

Mak, B. \& Coniam, D. (2008). Using wikis to enhance and develop writing skills among secondary school students in Hong Kong. System: An International Journal of Educational Technology and Applied Linguistics, 36 (3), 437-455.

Martín, M. y Alonso, L. (2009). La Universidad de Extremadura y su compromiso pedagógico con la educación virtual: los wikis como expresión de la web 2.0. RED. Revista de Educación a Distancia, Monográfico XI, 1-24

Met, M. (1998). Curriculum Decision-making in Content-based Language Teaching. En J. Cenoz y F. Genesee (eds.). Beyond bilingualism: multilingualism and multilingual education. (pp. 35-63). Clevedon: Multilingual Matters.

Morgan, B. \& Smith, R. D. (2008). A wiki for classroom writing. Reading Teacher, 62 (1), 80-82.

Morín, E. (1999). Los siete saberes necesarios para la educación del futuro. Consultado el 15/06/2011 en http://www.unmsn.edu.pe/occaa/articulos/saberes7.pdf.

Muñoz, C. (2000). Bilingualism and trilingüalism in school students in Catalonia. En J. Cenoz y U. Jessner (Ed.), English in Europe: the acquisition of a third language. Clevedon: Multilingual Matters.

Parker, K. y Chao, J. (2007). Wikis as a Teaching Tool. Interdisciplinary Journal of Knowledge and Learning objects, vol. 3, 57-72.

Peña, I., Córcoles, C. P., Casado, C. (2006). El Profesor 2.0: docencia e investigación desde la Red. UOC Papers 3. Consultado el 20/03/2010 en: http://www.uoc.edu/uocpapers/3/dt/esp/pena_corcoles_casado.pdf.

Prensky, M. (2001). Digital Natives, Digital Immigrants [onine]. On the Horizon, 9 (5). Consultado el 17/02/2011 en http://www.albertomattiacci.it/docs/did/Digital_Natives_Digital_Immigrants.pdf .

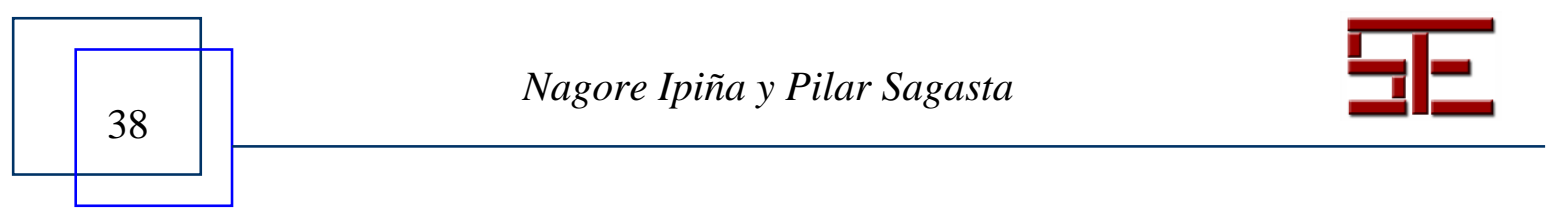




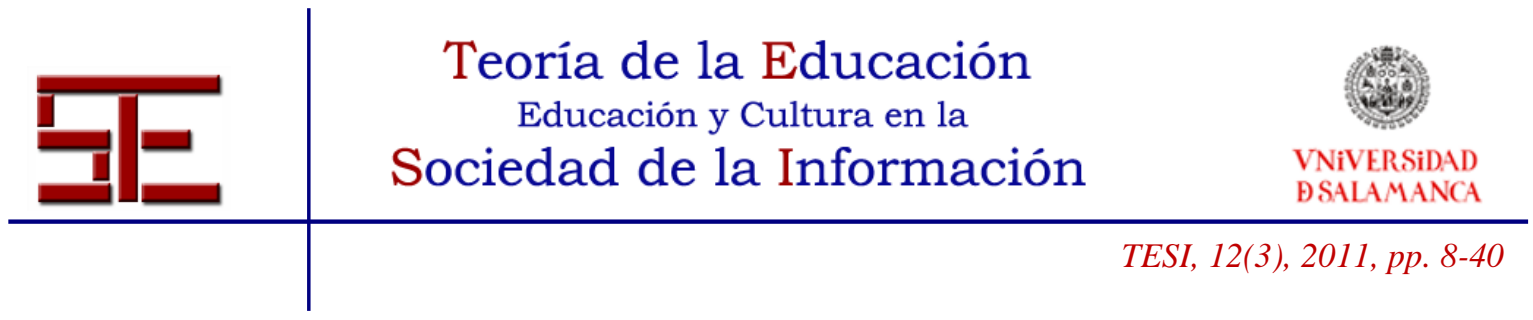

Ruiz de Zarobe, Y. y Lasagabaster, D. (2010). CLIL in a Bilingual Community. The Basque Autonomous Community. En D. Lasagabaster y Y. Ruiz de Zarobe (Ed.), CLIL in Spain. Implementation, Results and Teacher Training. 8pp. 12-29). Newcastle upon Tyne: Cambridge Scholars.

Sagasta, M. P. (2000). La producción escrita en euskara, castellano e inglés en el modelo D y en el modelo de Inmersión. Tesis Doctoral. Universidad del País Vasco. Euskal Herriko Unibertsitatea.

Sainz Osinaga, M. y Sagasta Errasti, M. P. (2005). Enseñando historia ¿enseñamos lengua? La integración de la lengua y las áreas del currículum en programas de inmersión. Revista d'Ensenyament Integrat de Llengües i Continguts, 7, 49-64.

Sanz, C. (2000). Bilingual education enhances third language acquisition: Evidence from Catalonia. Applied Psycholinguistics, 21, 23-44.

Schaffert, S., Bischof, D., Buerger, T., Gruber, A., Hilzensauer, W. \& Schaffert, S. (2006). Learning with semantic wikis. En Proceedings of the First Workshop on Semantic Wikis - From Wiki To Semantics (SemWiki2006), (pp. 109-123). Budva, Montenegro.

Serra Santasusana, T. (2004). Hablar de "mates" en clase. Uno. Revista de Didáctica de las matemáticas, 35, 23-38.

Schneider, D. K. (2004). Conception and implementation of rich pedagogical scenarios through collaborative portal sites. En Mario Tokoro \& Luc Steels (Ed.), The Future of Learning II, Sharing representations and Flow in Collaborative Learning Environment. IOS Press.

Short, D. J. (1991) How to integrate Language and Content Instruction. Washington: Center for Applied Linguistics.

Stahl, G. (2008). Integrating a wiki into support for group cognition. International Conference of the Learning Sciences (ICLS 2008), Utrecht. Consultado el 20/05/2009 en: http://gerrystahl.net/pub/icls2008wiki.pdf.

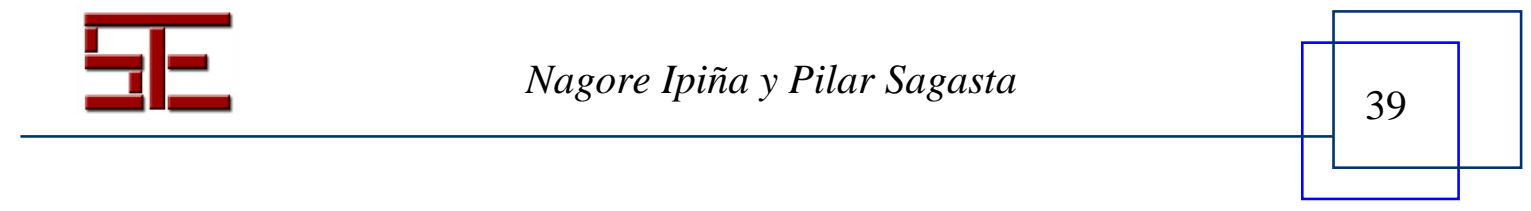




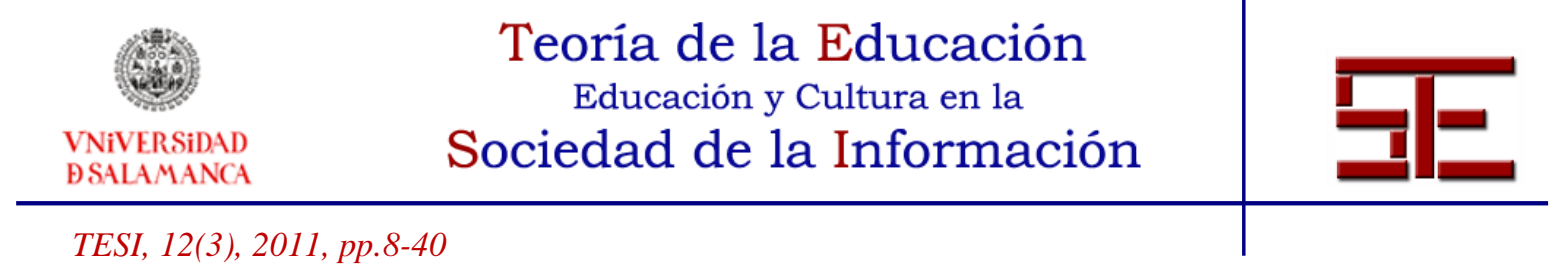

Swain, M. (2000). The output hypothesis and beyond: Mediating acquisition through collaborative dialogue. En J. P. Lantolf (Ed.), Sociocultural theory and Second Language Learning. (pp. 97-104). Oxford: Oxford University Press.

Swain, M., Lapkin, S., Rowen, N. \& Hart, D. (1990). The role of mother tongue literacy in third language learning. Language, Culture and Curriculum, 3, 65-81.

Tapscott, D. (1998). Growing Up Digital: The Rise of the Net Generation. Nueva York: McGraw-Hill.

Thomas, J. (1988). The role played by metalinguistic awareness in second and third language learning. Journal of Multilingual and Multicultural Development, 9, 235-246.

Toker, S.; Moseley, J. L. y Chow, A. T. (2008). Is There a Wiki in Your Future?: Applications for Education, Instructional Design, and General Use. Educational Technology Publications, 48 (5), 22-27.

Trentin, G. (2009). Using a Wiki to Evaluate Individual Contribution to a Collaborative Learning Project. Journal of Computer Assisted Learning, 25 (1), 43-55.

Xiao, Y. \& Lucking, R. (2008). The impact of two types of peer assessment on students' performance and satisfaction within a wiki environment. Internet and Higher Education, 11 (3-4), 186-193.

Para citar el presente artículo puede utilizar la siguiente referencia:

Ipiña, N. y Sagasta, P. (2011). La contribución de las nuevas tecnologías a la educación plurilingüie de los futuros docentes en comunidades con lengua minoritaria. Revista Teoría de la Educación: Educación y Cultura en la Sociedad de la Información. 12(3), 8-40 [Fecha de consulta: dd/mm/aaaa].

http://campus.usal.es/ revistas_trabajo/index.php/revistatesi/article/view/8481/8574 